\title{
Flight Deck Heat Spreader
}

\author{
Tadej Semenic ${ }^{\mathrm{a}, *}$, Kyle D. Gould ${ }^{\mathrm{a}}$, and Ya-Chi Chen ${ }^{\mathrm{a}}$ \\ ${ }^{a}$ Teledyne Scientific \& Imaging, 1049 Camino Dos Rios, Thousand Oaks, California 91360, USA
}

\begin{abstract}
Deployment of modern aircrafts such as MV-22 Osprey or F35B Joint Strike Fighter has caused buckling of aircraft carrier ship flight decks due to excessive heat impact from aircraft engine exhaust plumes during landing. This work describes a development of Flight Deck Heat Spreader (FDHS) that is placed over a flight deck landing spot to protect it from hot exhaust plumes. The FDHS consists of aluminum panels with supporting pillars, aluminum wick sintered directly to panels and supporting pillars, water with corrosion inhibitor working fluid, and is sealed by welding together individual panels. The FDHS operates similar to a vapor chamber i.e. water vapor spreads the heat. The FDHS has $60 \%$ of the weight of solid aluminum of the same size, it is rigid with good strength and mechanical impact loading resistance, and it can be scaled to large areas of more than $50 \mathrm{~m}^{2}$. This paper focuses on thermal modeling of the FDHS, fabrication and tests of $450 \mathrm{~cm}^{2}$ and $3721 \mathrm{~cm}^{2}$ FDHS prototypes, and selection of working fluid corrosion inhibitor. FDHS was demonstrated to effectively shield the flight deck during high temperature thermal exposure and that the FDHS cools 8-times faster than similar weight aluminum alloy plate.
\end{abstract}

Keywords: flight deck heat spreader and heat shield, aluminum sintered wick, corrosion inhibitor

\section{Introduction}

Deployment of modern aircrafts such as MV-22 Osprey or F35B Joint Strike Fighter has caused buckling of aircraft carrier ship flight decks due to excessive heat impact from aircraft engine exhaust plumes during landing. As a result, the flight deck landing area has to be replaced frequently resulting in long down times and high costs.

Flight decks are made of carbon steel which has low thermal conductivity and is poor heat spreader material. There is a need for lightweight, high thermal conductivity heat spreader and heat shield with an area of around $50 \mathrm{~m}^{2}$ that shall be placed on the flight deck landing area to shield it from high temperature exhaust plumes.

A brief literature survey of heat spreader materials that could potentially be used for flight deck thermal management system was performed. Four different types of heat spreader materials were identified. They are cellular structures, porous metals with phase change material, heat pipes embedded into panels and flat heat pipes or vapor chambers. Cellular materials are ultralight structures with excellent mechanical properties [1-3]; however, they have poor heat spreading capability because of high porosity. Porous metals with phase change material have good

\footnotetext{
${ }^{*}$ Corresponding author. Tel.: +1 805373 4118. E-mail address: tadej.semenic@teledyne.com
} 
performance in terms of heat storage and mechanical properties [4]; however, they are expected to be poor heat spreader material for flight deck thermal management because of low thermal conductivity of the phase change material. Heat pipes were successfully embedded into satellite load carrying structures and radiator panels and were reported to provide large savings in satellite volume and mass $[5,6]$. Heat pipes embedded into lightweight panes such as aluminum panels could form a good heat spreader material for a flight deck. However, it is not clear how to transfer heat between adjacent panels with heat pipes embedded into them. Also heat pipes underneath the high temperature plumes might not operate because of high heat loads that may exceed heat pipe boiling or capillary limit. An aluminum flat heat pipe or vapor chamber with nickel foam wick, water as working fluid, and an array of supporting crosses was demonstrated to provide good heat spreading and also it offers good structural load support [7]. This could be good technology to form flight deck heat spreader; however, durability of this heat spreader is not clear because the nickel foam wick is not bonded to the panel, but rather held by supporting crosses.

Present work describes a development of Flight Deck Heat Spreader (FDHS) that consists of aluminum panels with supporting pillars, aluminum wick sintered directly to panels and supporting pillars, water with corrosion inhibitor working fluid, and is sealed by welding individual panels together. The FDHS operates similar to a vapor chamber (i.e. water vapor spreads the heat), it is lighter than solid aluminum of the same size, it is rigid with good strength and mechanical impact loading resistance, and it can be scaled up to an area of $50 \mathrm{~m}^{2}$. This paper focuses on thermal modeling of the FDHS, fabrication and tests of $300 \mathrm{~mm} \times 150 \mathrm{~mm}$ and 610 mm x 610 mm FDHS samples, and selection of working fluid corrosion inhibitor.

\section{Flight Deck Heat Spreader (FDHS) concept}

FDHS is mounted to a flight deck landing spot using aircraft tie-downs. The FDHS is formed from multiple panels that are sealed at joints. The panels have supporting pillars and aluminum wick sintered directly to panels and supporting pillars. The heat spreader is charged with water that contains corrosion inhibitor. Corrosion inhibitor is required to suppress reaction between high surface area aluminum wick and water (more discussion in section 4). Individual panels are joined by welding to form leak tight seal that prevents air from enter the heat spreader and that contains the working fluid inside the heat spreader. After the assembly, the FDHS total thickness is $25 \mathrm{~mm}$ which is maximum thickness still acceptable without interfering with flight deck structures.

A concept of the FDHS is illustrated in Figure 1. During aircraft landing, hot exhaust plumes impinge on the FDHS, the heat is conducted through the panels and supporting pillars to the liquid saturated wick and vaporizes the liquid. Vapor rapidly flows away from the heat impingement zone and spreads the heat to the entire FDHS. The vapor condenses and rejects the heat at low heat flux to the ambient air or flight deck while the condensate drips into the continuous liquid pool formed on the bottom of the FDHS. The evaporated liquid is continuously replenished through the pillar wick (the wick formed on the supporting pillars) by capillary pumping of the fluid from the continuous liquid pool.

A structural modeling of FDHS was performed. The model determined that top panel thickness 6 $\mathrm{mm}$, bottom panel thickness $3 \mathrm{~mm}$, pillar diameter $13 \mathrm{~mm}$, pillar spacing $32 \mathrm{~mm}$ are required to 
meet the structural requirements resulting in acceptable heat spreader deformation during aircraft landing. Details of the structural model are beyond the scope of this paper.

Different candidate materials for FDHS panels and pillars were compared. It was determined that Al alloys 5-thousand series AA5454 and AA5052 have the best properties in terms of good corrosion resistance, high thermal conductivity, and high material liquidus temperature (required for sintering of the wick to achieve good wick adhesion).

FDHS offers several benefits: (1) it is modular and it can be assembled into FDHS of any size; (2) it is lightweight since it has hollow core that is used for vapor transport (16 mm out of $25 \mathrm{~mm}$ is hollow); (3) it has high lateral thermal conductivity (few tens of thousands of watts-per-meterKelvin) as a result of using vapor to transfer the heat; and (4) it is designed to sustain aircraft landing without plastic deformation of the supporting pillars or panels.

\section{Thermal model}

A jet impingement model of hot gas on the FDHS placed over a flight deck was developed. A flight deck without the FDHS was also modeled for comparison. Boundary conditions for the thermal model were provided by a customer. The customer performed a careful scaling analysis to determine boundary conditions of a subscale system with a $25 \mathrm{~mm}$ diameter nozzle. Flight deck size was determined to be $762 \mathrm{~mm}$ x $914 \mathrm{~mm}$ and nozzle to flight deck (or FDHS) distance $229 \mathrm{~mm}$. Nozzle exit velocity was determined to be $792 \mathrm{~m} / \mathrm{s}$, nozzle exit temperature $967{ }^{\circ} \mathrm{C}$, and duration of thermal exposure 5 seconds. Total number of thermal exposures was determined to be six and every thermal exposure was followed by 300 seconds of cooling in ambient air. The customer verified that the peak flight deck temperature under the subscale nozzle closely match the peak temperature under the actual aircraft exhaust nozzle. Geometry of the thermal model along with boundary conditions is shown in Figure 2.

Three different cases were modeled. In the first case, we modeled hot gas impingement on 13mm thick carbon steel plate (representing the flight deck), in the second case, we modeled hot gas impingement on $25 \mathrm{~mm}$ x $610 \mathrm{~mm}$ x $610 \mathrm{~mm} \mathrm{Al}$ alloy 5454 (AA5454) plate placed over the flight deck and in the third case we modeled hot gas impingement on $25 \mathrm{~mm}$ x $610 \mathrm{~mm}$ x 610 mm FDHS placed over the flight deck. The model also included silicon rubber with thickness 1.6 $\mathrm{mm}$ and thermal conductivity $0.2 \mathrm{~W} / \mathrm{m} \cdot \mathrm{K}$ between the heat spreader and flight deck. The rubber is required to prevent seawater from wicking underneath the FDHS. Modeling was performed with Fluent ANSYS. Hot plumes were modeled as air. Air and solid material properties were modeled as temperature dependent. Actual FDHS geometry including FDHS panel, supporting pillars, wicks, and vapor space was modeled. Wick thermal conductivity was specified as 20 $\mathrm{W} / \mathrm{m} \cdot \mathrm{K}$ (determined by the experiment) and vapor core thermal conductivity was assumed to be $200,000 \mathrm{~W} / \mathrm{m} \cdot \mathrm{K}$. It should be noted that dominating thermal resistances of the FDHS are panel thermal resistance and wick thermal resistance. Mesh independency was verified.

Temperature histories for maximum top and bottom flight deck temperature for the six thermal exposures are plotted in Figure 3.

We can notice that peak temperature on top of the carbon steel plate exceeds $760{ }^{\circ} \mathrm{C}$ (after the last thermal exposure). This temperature is above carbon steel annealing temperature (550-700 ${ }^{\circ} \mathrm{C}$ ) which explains thermal buckling that occurs on the flight deck. 
Next, we modeled temperatures of AA5454 plate and FDHS atop the flight deck. Temperature histories for maximum top AA5454 temperature and maximum top FDHS temperature are plotted in Figure 4. We can see that top surface temperature reaches $556{ }^{\circ} \mathrm{C}$ when AA5454 is placed on top of the flight deck and $253{ }^{\circ} \mathrm{C}$ when FDHS is placed on top of the flight deck. AA5454 maximum temperature approaches its melting point and far exceeds the annealing temperature for AA5454. We can conclude that $25 \mathrm{~mm}$ thick AA5454 heat spreader is not an option.

Temperature contours of AA5454 and FDHS after the last sixth heating cycle are plotted in Figure 5. We can notice that flight deck maximum temperatures are significantly reduced when placing a heat spreader on top of the flight deck. Maximum flight deck temperature is $74{ }^{\circ} \mathrm{C}$ when AA5454 is on top of the flight deck and $56^{\circ} \mathrm{C}$ when FDHS is on top of the flight deck. We can also notice that vapor temperature inside FDHS reaches around $110^{\circ} \mathrm{C}$. From thermal modeling study, we can conclude that FDHS will reduce top surface temperature from $760{ }^{\circ} \mathrm{C}$ (without heat spreader) to $253{ }^{\circ} \mathrm{C}$ and keep carbon steel temperature below $56{ }^{\circ} \mathrm{C}$ preventing flight deck buckling.

We calculated that $154 \mathrm{~kW}$ of heat exits the nozzle. We believe that portion of this heat is absorbed by the heat spreader and is spread to a larger area. In the event that heat flux exceeds capillary limit heat flux and wick dries out and that $75 \%$ of the heat is absorbed by the heat spreader, we calculated that it would take 1.6 seconds to reach saturation (boiling) temperature and that vaporization of water lasts 3 seconds. For the remaining 0.4 seconds, the wick will be dry. It takes slightly less than 2 seconds to replenish the wick with fresh liquid. The 300 seconds of cooling is more than enough to transport the liquid back to the (dry) wick.

\section{FDHS prototype fabrication}

FDHS samples with two different sample sizes were fabricated. The first were $300 \mathrm{~mm}$ x 150 mm samples that were formed from a single panel and were used for working fluid compatibility tests. The second was a $610 \mathrm{~mm}$ x $610 \mathrm{~mm}$ sample that was formed from multiple panels and was used for the thermal exposure test. For simplicity, the samples were sealed with silicone rubber gaskets and screws rather than welding of the panels. Air remained inside the FDHS. One of the FDHS panels included a pressure relief valve that was used to exhaust air from the FDHS when the internal pressure of vapor and air exceeded the valve set point. Residual air in the FDHS degraded the performance; however, having rubber gaskets allowed us to be able to easily disassemble the FDHS and inspect the internal structure after the test or replace panels if needed.

Panels with supporting pillars were fabricated from AA5454 plates by CNC machining. Wick was formed by pressing aluminum powders from Ecka Granules [11] with diameter 100-200 $\mu \mathrm{m}$ to aluminum panels and supporting pillars and then sintering them together. The wick porosity was 0.4 and the wick thickness was $1 \mathrm{~mm}$ on the face of the panel and $1.6 \mathrm{~mm}$ around the pillars. A photograph of one of the panels with a sintered aluminum wick is shown in Figure 6 . Figure $6 \mathrm{c}$ and Figure 6d show scanning electron microscope (SEM) photographs of the wick from which we can see that the wick has large particle-to-particle contact areas that are good for transferring heat at low thermal resistance, and also multiple connected pores around the particles that are good for transferring liquid at low flow resistance. 


\subsection{Working fluid compatibility test samples}

Thermal model determined that internal temperature of FDHS will be in around $110^{\circ} \mathrm{C}$. Water has superior thermophysical properties in a temperature range from $20^{\circ} \mathrm{C}$ to $200^{\circ} \mathrm{C}$ compared to other working fluids; however, aluminum and aluminum alloys reduce water to hydrogen $[8,9]$, which collects as a thermal insulating gas at the condenser and increases the overall heat spreader thermal resistance [10]. Three methods to minimize or eliminate hydrogen generation in an aqueous environment were evaluated: (1) nickel plating of panels with wick; (2) hard anodization of panels with wick; and (3) the use of corrosion inhibitors that promote the chemical conversion coating of both the wick and the panel surface. Additional discussion about hydrogen generation in an aqueous environment and the mechanism of chemical conversion coating can be found in the Appendix.

Fourteen $300 \mathrm{~mm} \times 150 \mathrm{~mm}$ aluminum alloy top panels with sintered aluminum powder wick were fabricated. One of the panels with the wick was nickel plated and one hard anodized. Each of the top panels included an integrated pressure relief valve (Swagelok SS-4C-KZ-30) for exhausting air and hydrogen from the FDHS. Bottom panels with the same footprint as the top panels were machined from AA5083 plate and were hard anodized after machining. The bottom panels were each equipped with a pressure transducer (Omega PX219-30V45G5V) and a thermocouple probe (Omega KMTSS-062U-6). The bottom panels were charged with $200 \mathrm{~g}$ of working fluid and bolted to the top panels. Silicone rubber gasket with durometer 40A was used to form a seal between the top and the bottom panel. It should be noted that air remained in the FDHS samples. After tightening the bolts, the sample total thickness was $25 \mathrm{~mm}$. Combinations of samples and working fluids is given in Table 1. The working fluids were prepared based on recommendations provided by the manufacturers [12-16]. Description of corrosion inhibitors is given in Appendix.

\subsection{FDHS sample for thermal exposure test}

A $610 \mathrm{~mm}$ x $610 \mathrm{~mm}$ x $25 \mathrm{~mm}$ FDHS sample was fabricated from a single bottom panel and nine top panels with three different panel sizes. Every second top panel had a silicone gasket adhered to its edges. The bottom panel formed a cavity for liquid and included supporting bridges with passages for liquid and vapor. Fabrication and assembly steps of the $610 \mathrm{~mm}$ x 610 mm x $25 \mathrm{~mm}$ sample are shown in Figure 7.

A pressure relief valve was installed in one of the corner top panels. The top panels were bolted to the bottom panel with supporting bridges in-between. A $1.6 \mathrm{~mm}$ thick rubber sheet was bonded to the bottom of the FDHS. The FDHS prototype was charged with $1.5 \mathrm{~kg}$ deionized ultra-filtered water. No corrosion inhibitors were used inside FDHS sample for the thermal exposure test because this study was performed in parallel to the working fluid and corrosion inhibitor study. The final prototype weight was $15.7 \mathrm{~kg}$. For comparison, the weight of the same size AA5454 plate is $25.4 \mathrm{~kg}$ and the weight of same size copper plate is $83.2 \mathrm{~kg}$.

\section{FDHS test setup}

Two different test setups were built to evaluate performance of FDHS samples. The first test setup was for $300 \mathrm{~mm}$ x $150 \mathrm{~mm}$ samples and it used an electric heater on one side of the sample and a cold plate on the opposite side of the sample to determine FDHS thermal resistance and effective thermal conductivity for different working fluids. An aluminum block with the same 
size as FDHS samples was also tested for comparison and for validation of the test. FDHS samples also included a pressure transducer that was used to measure pressure built up inside the sample. The difference between final and initial pressure inside the sample was due to hydrogen generation. The final pressure was always either equal to atmospheric pressure (if no hydrogen or insignificant amount of hydrogen was formed) or higher than the atmospheric pressure if significant amount of hydrogen was formed.

The second test setup was thermal exposure test setup that was used to test $610 \mathrm{~mm} \times 610 \mathrm{~mm}$ FDHS sample and carbon steel plate for comparison. The test provided important information about FDHS operation and heat shielding of carbon steel plate; however, it did not simulate well aircraft landing because it used an order of magnitude lower heat load than the thermal model in section 3.

\subsection{Test setup for $150 \mathrm{~mm}$ x $300 \mathrm{~mm}$ FDHS samples}

Each of the samples was placed on an insulated test stand, a thermally insulated electrical heater with a diameter of $45 \mathrm{~mm}$ was clamped on one side of the sample, and a cold plate (Lytron CP10G14) was clamped on the opposite side as shown in Figure 8.

Each sample included a $0.8 \mathrm{~mm}$ wide and $0.8 \mathrm{~mm}$ deep groove right underneath the center of the heater. A thermocouple (Omega TMTSS-032U-6) was inserted into the groove for measuring the evaporator wall temperature $\left(\mathrm{T}_{6}\right)$. An additional thermocouple was attached using Kapton tape underneath the center of the cold plate for the purpose of measuring the condenser wall temperature $\left(\mathrm{T}_{7}\right)$. A thermal pad was used underneath the cold plate and thermal grease was used underneath the heater to minimize interfacial thermal resistances. The entire test setup was well insulated (thermal conductivity of the insulation was $0.02 \mathrm{~W} / \mathrm{m} \cdot \mathrm{K}$ ).

Tests were performed at two different heat loads. First, the power to the heater was adjusted to $240 \mathrm{~W}\left(15 \mathrm{~W} / \mathrm{cm}^{2}\right.$ evaporator heat flux $)$ and the sample was heated for 30 minutes and cooled to room temperature (Test 1), which took another 30 minutes. During the Test 1, or wick passivation process, hydrogen was allowed to form. The Pressure Relief Valve (PRV) was opened after Test 1 to vent any hydrogen that generated during the process. Next, the PRV was capped and the sample was again heated using the same heating profile as Test 1 . Any pressure increase during Test 2 indicated the generation of hydrogen and poor performance of the wick coating or the corrosion inhibitor. It should be mentioned that after Test 1 most likely some residual hydrogen remained inside the sample. However, prior to Test 2 total pressure of all the gases and vapor inside the sample was equal to the atmospheric pressure. The aim of the Test 2 was to determine total pressure increase during the test.

After the second test, the samples with minimal or no hydrogen generated were retested at 440 $\mathrm{W}\left(28 \mathrm{~W} / \mathrm{cm}^{2}\right.$ evaporator heat flux). During this test (Test 3), the PRV cap was removed and the PRV was allowed to open if the pressure exceeded the PRV cracking pressure (above $308 \mathrm{kPa}$ ). An aluminum alloy 6061 block with the same dimension as the MHS samples was also tested at both power levels for comparison. For each of the tests, steady state was reached approximately after 10 minutes of heating. Temperatures for the last five minutes of heating were averaged and used to calculate the sample thermal resistance, $R$, at a given heat load. Thermal resistance was calculated as, 


$$
R=\frac{T_{6}-T_{7}}{k_{c u} \frac{\Delta T}{\Delta x} A_{\text {heater }}}
$$

where $T_{6}$ is the evaporator wall temperature, $T_{7}$ is the condenser wall temperature, $k_{C u}$ is thermal conductivity of copper [18], $\Delta T / \Delta x$, is temperature gradient inside the heater that was obtained from linear regression on temperature readings $T_{1}$ to $T_{5}, A_{\text {heater }}$ is the area of the heater. The locations of the thermocouples $T_{1}$ to $T_{7}$ are shown in Figure 8. Pressure build up was calculated as the difference between the pressure measured at the end of the test inside the sample minus the pressure inside the sample at the beginning of the test (or ambient pressure).

\subsection{Test setup for the $610 \mathrm{~mm} \times 610 \mathrm{~mm}$ FDHS sample}

A thermal exposure test setup with a large enclosure, a propane torch and a carbon steel plate was built to test the $610 \mathrm{~mm} \times 610 \mathrm{~mm}$ FDHS sample. A schematic and a photograph of the thermal exposure test setup are shown in Figure 9.

The enclosure size was $960 \mathrm{~mm} \times 810 \mathrm{~mm}$ x $610 \mathrm{~mm}$ and it was formed from $6 \mathrm{~mm}$ thick polycarbonate. The size of the carbon steel plate was $13 \mathrm{~mm}$ x $762 \mathrm{~mm}$ x $914 \mathrm{~mm}$ and it was insulated underneath (thermal conductivity of the insulation was $0.02 \mathrm{~W} / \mathrm{m} \cdot \mathrm{K}$ ). The top of the enclosure included two vents (openings) for exhausting hot gases from the enclosure. A $29 \mathrm{~mm}$ diameter propane nozzle (McMaster-Carr 78505A23) connected to compressed air and propane gas was used as a heat source. The FDHS sample was placed on the steel plate such that the nozzle pointed exactly toward the center of the sample. The distance between the nozzle and the sample was kept at $25 \mathrm{~mm}$.

Three thermocouples were used to monitor the temperature of the sample during the test. Thermocouple $\mathrm{T}_{1}$ (Omega KMTSS-125U-12) was located $3 \mathrm{~mm}$ above the center of the sample to measure flame ground plane impingement temperature, thermocouple $\mathrm{T}_{2}$ (Omega KMTSS062U-12) was pinned into a groove that was formed on the surface of the sample, and thermocouple $\mathrm{T}_{3}$ was attached to the backside of the steel plate. The tips of all three thermocouples were exactly aligned with the center of the sample. The locations of the thermocouples are shown in Figure 9c.

The propane gas pressure was adjusted to $379 \mathrm{kPa}$. At this pressure, the nozzle heating rate was $12.9 \mathrm{~kW}$ (for comparison thermal model in section 3 calculated that heat input for a subscale thermal exposure system is $154 \mathrm{~kW}$ ). The sample was heated six times for seven minutes and was allowed to cool for eight minutes between the six thermal exposures. Temperatures $T_{1}, T_{2}$, and $\mathrm{T}_{3}$ were recorded during the test. It should be noted that this test setup did not simulate well heating from the aircraft nozzle; however, it provided important insides about FDHS operation and shielding of the carbon steel plate. Experimental heating time was 7 minutes instead of 5 seconds (used for the thermal model in section 3) to match maximum carbon steel bottom temperature. The experiment used nozzle exit velocity of approximately $65 \mathrm{~m} / \mathrm{s}$ (for comparison thermal model in section 3 used nozzle exit velocity $792 \mathrm{~m} / \mathrm{s}$ ). Thermal exposure tests were performed by impinging the flame on the FDHS, on an aluminum plate with the same size as FDHS (for comparison), and directly on the carbon steel plate (baseline). 


\section{Results and discussion}

Three sets of results are presented and discussed in this section. The first are the results for working fluid compatibility tests. These results provide important findings on efficacy of different corrosion inhibitors on suppressing the reaction between water and aluminum. The second set of the results provides effective thermal conductivities for the FDHS samples with different working fluids and compares them to thermal conductivity of solid aluminum. The third are the results of the thermal exposure test for carbon steel plate, and the FDHS or the aluminum plate on top of the carbon steel plate.

\subsection{Working fluid compatibility test results}

The results for the hydrogen generation rates for the fourteen $300 \mathrm{~mm}$ x $150 \mathrm{~mm}$ FDHS samples listed in Table 1 are presented in Figure 10. Sample 1 did not have a wick and was also hard anodized. It did not generate any hydrogen. This test sample provided a validation of the test method. Samples 2 to 5 all had aluminum wicks and were tested with water (deionized ultrafiltered water); all four generated hydrogen. Samples 6 and 7 had an electroless Ni plated wick and a hard anodized wick, respectively. They both still generated hydrogen. Neither wick coating prevented hydrogen generation. Sample 8 tested with Inorganic Aqueous Solution (IAS) generated a small amount of hydrogen during the first test (passivation process) and zero or a non-measurable amount of hydrogen during the second test. Sample 9 tested with a solution of a $150 \mathrm{ppm}$ of chromic acid $\left(\mathrm{CrO}_{3}\right)$ resulted in hydrogen generation. The concentration of the $\mathrm{CrO}_{3}$ was likely too low to passivate the aluminum wick. Sample 10 tested with a solution of $500 \mathrm{ppm}$ of vapor phase corrosion inhibitor S10 generated significantly more hydrogen than any other working fluid. This was attributed to a higher concentration of hydroxyl ions $\left(\mathrm{OH}^{-}\right)$that promote hydrogen generation as discussed in [8]. Sample 11 tested with 1\% Vapor phase corrosion inhibitor 308 (VpCl-308) resulted in none or not measurable amount of hydrogen during the second test. VpCl-308 corrosion inhibitor was as effective as IAS in passivating the aluminum wick surface and preventing hydrogen generation. Sample 12 tested with 5\% Iridite Non Chrome Passivate (NCP) generated hydrogen during Test 2 and similarly sample 13, tested with 50\% propylene-glycol (PGW), also generated hydrogen. Samples 14 and 15 were tested with EPassivate Alumimum (AL) and Zerex automotive coolant, respectively, and were both very effective in suppressing hydrogen generation.

After the testing had been completed, visual inspections of samples were performed. On sample 9 (tested with $\mathrm{CrO}_{3}$ ), we noticed a yellow deposition while sample 8 (tested with IAS) exhibited a yellow to dark brown deposition on the wick in the evaporation section. A photograph of the evaporator wick for sample 8 is shown in Figure 11.

Kendig and Buchheit [13] reported that yellow to brown coatings observed on aluminum materials are associated with the deposition of the chromate. This also implies that a phase separation of water and chromates may have occurred in the evaporator and chromates deposited on the evaporator wick. Similar observations were made by Reilly et al. [12] who performed microscopy of the wick after being tested with IAS and noticed ligature shaped deposits on the wick surface.

It was somewhat unexpected that samples 6 and 7 both with wicks coated (by Ni plating or hard anodization) resulted in hydrogen generation. Samples of the evaporator wick were sectioned and visualized under the microscope. A photograph of both samples is shown in Figure 12. 
It was observed that neither of the coatings penetrated into the wick. Only the first layer of particles was coated. Since the coating did not penetrate into the wick, the majority of the wick remained uncoated, and resulted in samples 6 and 7 producing hydrogen during the test.

\subsection{Thermal conductivity test results}

Test results with $300 \mathrm{~mm} \times 150 \mathrm{~mm}$ FDHS samples were also used to determine the effective thermal conductivities of samples tested with different working fluids. Steady state temperatures recorded during the three tests were averaged and thermal resistances for different tests and samples were calculated using Equation (1). Thermal resistances are plotted in Figure 13. During Test 1 and Test 2, the Pressure Relief Valve (PRV) was closed and no gas was allowed to leave the sample. It should be noted that the air remained in all the samples which was very similar to the thermal exposure test of the $610 \mathrm{~mm}$ x $610 \mathrm{~mm}$ FDHS (discussed below). From Figure 13, we can observe that at $240 \mathrm{~W}\left(15 \mathrm{~W} / \mathrm{cm}^{2}\right.$ evaporator heat flux $)$ and PRV closed, all the samples performed worse than the same size AA6061 aluminum plate. This was primarily because of presence of air in the FDHS samples and in part also because a large portion of the evaporator was obstructed by the two supporting pillars (included to meet FDHS structural requirements) as shown in Figure 11. However, when the PRV was allowed to open and the heat load was increased to $440 \mathrm{~W}\left(28 \mathrm{~W} / \mathrm{cm}^{2}\right.$ evaporator heat flux) in Test 3, the FDHS samples performed better than the solid aluminum.

Finite Element Analysis (FEA) modeling using ANSYS IcePack was used to determine effective thermal conductivities of the FDHS samples. Experimentally measured temperatures were applied as boundary conditions and effective thermal conductivity was determined by matching modeled and experimentally measured temperatures. Temperature contours for an example calculation for the solid Al alloy block and sample 4 (tested with water) are shown in Figure 14. Thermal performances along with panel thermal conductivity $\left(\mathrm{k}_{\text {panel }}\right)$ and FDHS effective thermal conductivity ( $\mathrm{k}_{\mathrm{eff}}$ ) obtained with the FEA model for selected samples are summarized in Table 2.

From the Table 2, we can see that the highest effective thermal conductivity of $370 \mathrm{~W} / \mathrm{m} \cdot \mathrm{K}$ was achieved with the sample 4 that was tested with water. The second highest effective thermal conductivity of $310 \mathrm{~W} / \mathrm{m} \cdot \mathrm{K}$ had sample 8 that was tested with IAS. The third highest effective thermal conductivity of $240 \mathrm{~W} / \mathrm{m} \cdot \mathrm{K}$ had samples 11 and 14 that were tested with $1 \% \mathrm{VpCl}-308$ and $10 \%$ E-Passivate, respectively. Effective thermal conductivity for the sample 15 that was tested with Zerex was lower than the bulk thermal conductivity of AA6061. It should be noted that panel thermal conductivity for the sample 8 (tested with IAS) was higher than for the samples 11 and 14 (tested with 1\% VpCl-308 and 10\% E-Passivate) as shown in Table 2. Effective thermal conductivity for samples 11 and 14 will most likely be higher than $240 \mathrm{~W} / \mathrm{m} \cdot \mathrm{K}$ (perhaps close to $310 \mathrm{~W} / \mathrm{m} \cdot \mathrm{K}$ ) if using same alloy for the panels as used for the sample 8 .

\subsection{Thermal exposure test results}

The $610 \mathrm{~mm}$ x $610 \mathrm{~mm}$ FDHS sample with thickness of $25 \mathrm{~mm}$ and a weight of $15.7 \mathrm{~kg}$ and 610 $\mathrm{mm} \times 610 \mathrm{~mm}$ AA5083 plate with thickness $19 \mathrm{~mm}$ and a weight of $18.8 \mathrm{~kg}$ were both tested with the thermal exposure test bed. It was important to demonstrate the reduction of carbon steel 
plate temperature when it is shielded by FDHS or aluminum plate and also to demonstrate a high cooling rate of the heat spreader and low heat spreader top surface temperature.

During the tests, the flame ground plane impingement temperature $\left(T_{1}\right)$ measured an average of $1100^{\circ} \mathrm{C}$. Sample top surface temperature $\left(\mathrm{T}_{2}\right)$ and the bottom temperature of the carbon steel $\left(\mathrm{T}_{3}\right)$ were also measured during the test. Bottom temperature of the carbon steel for three different cases is plotted in Figure 15. By comparing bottom steel temperature from thermal simulation (Figure 3 and Figure 4) to experimentally measured temperature (Figure 15), we can notice that experiment measured maximum bottom carbon steel temperature of $395^{\circ} \mathrm{C}$. For comparison the model predicted $360^{\circ} \mathrm{C}$. With FDHS placed on top of the carbon steel, the experiment measured maximum carbon steel temperature of $94{ }^{\circ} \mathrm{C}$ and the model predicted 56 ${ }^{\circ} \mathrm{C}$. The experiment measured that when placing AA5083 plate on the carbon steel plate, the maximum steel bottom temperature is $103{ }^{\circ} \mathrm{C}$. Maximum FDHS and AA5083 top surface temperatures after the last sixth cycle were measured $176^{\circ} \mathrm{C}$ for FDHS and $209^{\circ} \mathrm{C}$ for AA5083, respectively. It should be noted that top surface temperature would be much higher if using same heating conditions than the thermal model in section 3 .

Figure 16 compares cooling rates of FDHS, AA5083, and carbon steel after the sixth heating cycle. MHS cooled to $125^{\circ} \mathrm{C}$ (i.e. maximum temperature to avoid melting of aircraft tires) in only 33 seconds, while the AA5083 plate cooled to $125^{\circ} \mathrm{C}$ in 275 seconds.

A numerical simulation of the thermal exposure test was also performed using ANSYS Fluent. First, the experimental data was used for $610 \mathrm{~mm}$ x $610 \mathrm{~mm}$ x $19 \mathrm{~mm}$ AA5083 to determine the nozzle outlet velocity by matching experimentally measured temperatures with the modeled temperatures. Using the known nozzle outlet temperature and velocity, we then modeled the performance of the $610 \mathrm{~mm}$ x $610 \mathrm{~mm}$ x $25 \mathrm{~mm}$ AA5454 plate (same volume as FDHS sample). AA5454 is the same aluminum alloy used for the FDHS panels. Modeled temperatures for the first heating cycle are compared to experimentally measured temperatures in Figure 17.

The AA5454 plate, with the same thickness as FDHS, reached a maximum top surface temperature of $132{ }^{\circ} \mathrm{C}$ while FDHS reached a maximum top surface temperature of $165^{\circ} \mathrm{C}$. This indicates that the effective thermal conductivity of FDHS is lower than that of AA5454. This is consistent with the results of the Test 2 with $300 \mathrm{~mm} \times 150 \mathrm{~mm}$ samples where the samples resulted in lower effective thermal conductivity than solid aluminum. Such low effective thermal conductivity is a result of the presence of air inside the FDHS. Test 3 with the $300 \mathrm{~mm} \times 150$ $\mathrm{mm}$ samples demonstrated that when the PRV is allowed to open and to vent the air, FDHS thermal conductivity becomes higher than $300 \mathrm{~W} / \mathrm{m} \cdot \mathrm{K}$ (higher than for solid aluminum).

To prevent fluid loss during thermal exposure tests, the PRV set point was increased. As a result, the PRV remained closed during the tests and all the air remained in the FDHS. In addition, because water was used as working fluid, hydrogen was generated during the heating and further increased the amount of non-condensable gas. We can expect that FDHS with air inside if subject to the same heating condition as modeled in section 3 (Figure 5), the FDHS top surface temperature will most likely exceed $556{ }^{\circ} \mathrm{C}$ approaching melting point of aluminum. Future work must improve FDHS sealing, remove non-condensable gases from the heat spreader, and use working fluid that is compatible with aluminum wick (i.e. water with corrosion inhibitor). 
It can be seen from Figure 17 that FDHS cools significantly faster than an AA5454 plate with the same thickness. In the first 30 seconds of cooling the FDHS, temperature is reduced by $54{ }^{\circ} \mathrm{C}$ while AA5454 plate is only reduced by $27^{\circ} \mathrm{C}$. This indicates that the effective specific heat of FDHS during cooling is slightly higher than that of AA5454. In the future when removing noncondensable gases from the FDHS, the cooling rate is expected to be even faster.

\section{Concluding remarks}

A lightweight and modular flight deck heat spreader (FDHS) was developed. The FDHS was formed from aluminum panels with supporting pillars and had aluminum powder wick sintered to the panels and supporting pillars. Different water based working fluids were investigated in this work. Thermal exposure testing was performed and the heat shielding effectiveness of the FDHS was compared to the same size aluminum plate.

The main conclusions of this work are:

- FDHS was very effective in reducing the flight deck temperature. The bottom flight deck temperature was reduced from $395^{\circ} \mathrm{C}$ to $94^{\circ} \mathrm{C}$ when shielded by the FDHS.

- Weight for $610 \mathrm{~mm}$ x $610 \mathrm{~mm}$ FDHS sample was $15.7 \mathrm{~kg}$. For comparison same size AA5454 plate weighs $25.4 \mathrm{~kg}$ and same size copper plate weighs $83.2 \mathrm{~kg}$.

- FDHS cools eight times faster than similar weight aluminum plate

- Inorganic Aqueous Solution (IAS) working fluid, aqueous solution of 1\% Vapor Phase Corrosion Inhibitor 308 (VpCl-308) and aqueous solution of 10\% E-Passivate are very effective in suppressing hydrogen generation when in contact with aluminum wick.

Future work should improve FDHS sealing. Welding should be used to form hermetic seals between panels instead of using screws and silicon gaskets. Long term working fluid compatibility test should be performed for the three most promising corrosion inhibitors (Inorganic Aqueous solution, Vapor Phase Corrosion Inhibitor VpCl-308 and E-Passivate AL). Thermal exposure test bed need to be improved to increase the heat load to the same level as used for the thermal model of the subscale aircraft nozzle.

\section{Acknowledgements}

The authors would like to acknowledge the support of the Office of Naval Research (grant contract number N00014-10-C-0252). The program officer was Dr. David A. Shifler. A U.S. patent was applied for this technology (patent application number US20130168057 A1). The authors would like to thank Dr. Bing Chung Chen, Dr. Qingjun (Steve) Cai, Dr. Martin Kendig from Teledyne Scientific \& Imaging, Dr. Chung-Lung Chen from University of Missouri, Dr. Scott Schroeder from Exponent, and Mr. Murray Mahoney from Advanced Metal Products, Inc. for suggestions and guidelines throughout the program. We would also like to extend our gratitude to Mr. Earl Presson, Mr. Stephen Clem, and Mr. Arnold Collet from Teledyne Brown Engineering for the support with structural modeling and design of the prototype. Thank you to Mr. Philip Brenneise for proofreading and editing of the manuscript. 


\section{Appendix}

\subsection{Mechanism of hydrogen generation and inhibition}

Aluminum and aluminum alloys directly react with water with the following chemical reactions [8]:

$2 \mathrm{Al}+6 \mathrm{H}_{2} \mathrm{O} \leftrightarrows 2 \mathrm{Al}(\mathrm{OH})_{3}+3 \mathrm{H}_{2}$

$2 \mathrm{Al}+4 \mathrm{H}_{2} \mathrm{O} \leftrightarrows 2 \mathrm{AlO}(\mathrm{OH})+3 \mathrm{H}_{2}$

$2 \mathrm{Al}+3 \mathrm{H}_{2} \mathrm{O} \leftrightarrows \mathrm{Al}_{2} \mathrm{O}_{3}+3 \mathrm{H}_{2}$

The first reaction is favorable from room temperature to $280{ }^{\circ} \mathrm{C}$ and its reaction rate is $8 \mathrm{E}-07 \mathrm{~g}$ $\mathrm{H}_{2} / \mathrm{sec} / \mathrm{g}$ of aluminum. The reactions between water and aluminum are highly exothermic with enthalpy of reaction of about $280 \mathrm{~kJ} / \mathrm{mol} \mathrm{H}_{2}$ at $50-100{ }^{\circ} \mathrm{C}$ [9]. In practice, however, aluminum oxide forms on the aluminum surface, which prevents the formation of hydrogen. Additionally, hydrogen generation technologies, which utilize the above reactions to form hydrogen, are mostly focused on approaches that can disrupt/remove the aluminum oxide layer $[8,9]$. In our tests, however, we observed that the aluminum oxide that formed on the wick surface was insufficient in suppressing hydrogen generation. Corrosion inhibitors were required to passivate the wick surface.

Kendig and Buchheit [13] provided a critical review of inhibition of aluminum (Al) corrosion by chromates. As explained, chromium inhibits Al corrosion by inhibition of oxygen reduction and inhibition of metal dissolution reactions mainly due to a delay in the onset of pitting. Chromium $\left(\mathrm{Cr}^{6+}\right)$ oxoanions are very soluble and mobile and are easily transported to sites of localized corrosion where they are reduced to $\mathrm{Cr}^{3+}$ and irreversibly adsorbed at metal surfaces. Another important property of $\mathrm{Cr}^{6+}$ oxoanions is their ability to adsorb on metal surfaces. Stored $\mathrm{Cr}^{6+}$ oxoanions can be slowly released into an attacking solution and stifle the corrosion. The authors [13] also discuss the process of chromium conversion coatings (CCCs) that have been found not only to provide very good barriers on aluminum alloys (e.g. by formation of chromium hydroxide coating), but also to repair defects and damage on the coating (self-healing effect). Unfortunately, the mobility of aqueous $\mathrm{Cr}^{6+}$ within biological systems and its reactivity with biochemical oxidation mediators make it both highly toxic and carcinogenic. It is believed that molecular debris associated with the process of $\mathrm{Cr}^{6+}$ to $\mathrm{Cr}^{3+}$ reduction induces critical changes in DNA. It should be mentioned that corrosion inhibitor E-passivate Al [15] is biodegradable and is based on trivalent chromium that is friendly to biological systems.

\subsection{Compositions of corrosion inhibitors used in this work}

Inorganic Aqueous Solution (IAS) [12] consists of the following chemicals: $\mathrm{KMnO}_{4}, \mathrm{CaCr}_{2} \mathrm{O}_{7}$, $\mathrm{SrCr}_{2} \mathrm{O}_{7}, \mathrm{MgCr}_{2} \mathrm{O}_{7}, \mathrm{Ag}_{2} \mathrm{Cr}_{2} \mathrm{O}_{7}, \mathrm{~K}_{2} \mathrm{Cr}_{2} \mathrm{O}_{7}$, and $\mathrm{K}_{2} \mathrm{CrO}_{4}$. Iridite $\mathrm{NCP}$ [14] contains aluminum, fluoride and oxygen. E-passivate $\mathrm{AL}$ [15] is an aqueous solution of nitric acid, chromium hydroxide sulfate $\left(\mathrm{Cr}(\mathrm{OH}) \mathrm{SO}_{4}\right)$, and ammonium bifluoride. $\mathrm{VpCl}-308$ [16] is biodegradable vapor phase corrosion inhibitor for corrosion protection of ferrous and non-ferrous metals. The inhibitor forms a monomolecular inhibiting layer and is distributed and deposited by vapor. S10 [16] is similar to $\mathrm{VpCl}-308$; however, it has relatively high $\mathrm{pH}$ (10.5 to 11.5) and is mostly used to neutralize systems with high content of carbonic acid. 


\section{References}

[1] A.G. Evans, J.W. Hutchinson, M.F. Ashby, Multifunctionality of cellular metal systems, Progress Mtls Sci 1999; 43:171-221

[2] A.G. Evans, J.W. Hutchinson, N.A. Fleck, M.F. Ashby, H.N.G. Wadley, The topological design of multifunctional cellular metals, Progress Mtls Sci 2001; 46:309-327

[3] H.N.G. Wadley, Multifunctional periodic cellular metals, Phil. Trans. R. Soc. A 2006; $364: 31-68$

[4] R. Wirtz, T. Zhao, Y. Jiang, Thermal and Mechanical Characteristics of a Multifunctional Thermal Energy Storage Structure, IEEE Trans Component Packaging Techno 2009; 32(1):5362

[5] G. S. Aglietti, C. W. Schwingshackl, and S. C. Roberts, Multifunctional Structure Technologies for Satellite Applications, The Shock and Vibration Digest 2007; 39(5):381-391

[6] T. Stern, W. G. Anderson, High temperature lightweight heat pipe panel technology development, Proc. of Space Nuclear Conf. 2005; Paper 1129, San Diego, California, June 5-9, 2005.

[7] D. T. Queheillalt, G. Carbajal, G.P. Peterson, H. N. G. Wadley, A multifunctional heat pipe sandwich panel structure, Int. J. Heat Mass Transfer 2008; 51:312-326

[8] H.Z. Wang, D.Y.C. Leung, M.K.H. Leung, M. Ni, A review on hydrogen production using aluminum and aluminum alloys, Renew Sust Energ Rev 2009; 13:845-853

[9] J. Petrovic and G. Thomas, Reaction of Aluminum with Water to Produce Hydrogen, DOE Report 2008; www1.eere.energy.gov/hydrogenandfuelcells/pdfs/aluminium_water_hydrogen.pdf

[10] G.F. Pittinato, Hydrogen gas generation in water heat pipes, J. Eng. Mater. Technol. 1978; 100(3):313-318.

[11] Ecka Granules Metal-Powder-Technologies, (www.ecka-granules.com)

[12] S. Reilly, L. Amouzegar, H.T. Tao, I. Catton, Use of Inorganic Aqueous Solutions for Passivation of Heat Transfer Devices, Proc. Of $10^{\text {th }}$ IHPS Taipei, Taiwan 2011; 153-157

[13] M.W. Kendig and R.G. Buchheit, Corrosion Inhibition of Aluminum and Aluminum Alloys by Soluble Chromates, Chromate Coatings, and Chromate-Free Coatings, Corrosion; 2003; 59(5):379-400.

[14] R. Bauer and J. Girard, Iridite NCP: A Comparison Of Iridite NCP to Yellow Chromate, MacDermid Industrial Solutions 2004 (www.industrial.macdermid.com)

[15] E-PASSivate AL, EPI-0201 Material Safety Data Sheet, 2011 EPi (www.epi.com)

[16] VpCl-308 and S10 product specifications 2008, Cortec (www.cortecvci.com)

[17] Coating System, Non-Skid, for Roll, Spray, or Self-Adhering Application, MIL-PRF24667C Section 4.5.3, 2008 
[18] MatWeb Material Property Data (www.matweb.com)

\section{Figure Captions}

Figure 1: Flight Deck Heat Spreader (FDHS). Aircraft exhaust plumes impinge on top panel and vaporize working fluid absorbed in sintered aluminum wick; vapor spreads the heat to panels away from the heat source, and rejects the heat to ambient and flight deck at low heat flux over a large area. Working fluid condenses and drips into a liquid pool formed on the bottom of the FDHS and the condensate is wicked back to the evaporator wick located underneath the heat source.

Figure 2: Geometry and boundary conditions of subscale flight deck thermal model. Nozzle exit velocity is $792 \mathrm{~m} / \mathrm{s}$ and nozzle exit temperature is $977^{\circ} \mathrm{C}$. Nozzle diameter is $25 \mathrm{~mm}$ and nozzle height is $229 \mathrm{~mm}$. Carbon steel plate size is $13 \mathrm{~mm} \times 762 \mathrm{~mm} \times 914 \mathrm{~mm}$ and heat spreader size is $25 \mathrm{~mm} \times 610 \mathrm{~mm} \times 610 \mathrm{~mm}$.

Figure 3: Temperature history of maximum top and bottom temperatures of carbon steel flight deck. Carbon steel flight deck was subjected to 5 seconds long thermal exposures with hot air at $967^{\circ} \mathrm{C}$ and air velocity $792 \mathrm{~m} / \mathrm{s}$. Maximum top plate temperature reached $760^{\circ} \mathrm{C}$ and maximum bottom plate temperature $360^{\circ} \mathrm{C}$.

Figure 4: Temperature history of maximum AA5454 and FDHS top temperatures. FDHS and AA5454 were both subjected to 5 seconds long thermal exposures with hot air at $967^{\circ} \mathrm{C}$ and air velocity $792 \mathrm{~m} / \mathrm{s}$. Maximum top plate temperature reached $556{ }^{\circ} \mathrm{C}$ for AA5454 plate and $253{ }^{\circ} \mathrm{C}$ for FDHS.

Figure 5: Temperature contours at the end of the last sixth heating cycle; (a) AA5454 plate, (b) FDHS heat spreader. Maximum top surface temperature reached $556{ }^{\circ} \mathrm{C}$ for the AA5454 plate and $253{ }^{\circ} \mathrm{C}$ for the FDHS. Maximum bottom surface temperature reached $74{ }^{\circ} \mathrm{C}$ for the AA5454 plate and $56^{\circ} \mathrm{C}$ for the FDHS.

Figure 6: Aluminum powder wick sintered to one of the FDHS top panels. (a) Photograph of a $300 \mathrm{~mm} \times 150 \mathrm{~mm}$ FDHS panel with wick, (b) a close-up photograph of pillars with wick, (c) and (d) are scanning electron microscope photographs of the wick fracture showing individual particle-to-particle contacts.

Figure 7: FDHS fabrication and assembly steps. (a) Panel machining, (b) wick fabrication, (c) gasket adhesion to a panel, (d) FDHS liquid charging and panel assembly (for clarity only two of the nine top panels are shown). 
Figure 8: Test setup for working fluid compatibility tests. Heater block with an array of equally spaced thermocouples $T_{1}$ to $T_{5}$ is used to measure the heat flux into the FDHS sample.

Evaporator surface temperature is measured with thermocouple $T_{6}$. A cold plate is used to remove the heat from the FDHS sample. Condenser temperature is measured with thermocouple $T_{7}$. Internal pressure of the sample is monitored with a pressure transducer (not shown for clarity).

Figure 9: Thermal exposure test bed. (a) Schematic of the thermal exposure test setup. FDHS sample is placed on a carbon steel plate that simulates a flight deck. Propane torch is used to heat the sample. Flame impinges on the FDHS and the FDHS spreads the heat and shields the carbon steel plate. (b) Photograph of the test bed. (c) Detail of the heat impingement zone showing the locations of the thermocouples. Thermocouple $T_{1}$ is used to measure ground plane impingement temperature, thermocouple $T_{2}$ is used to measure sample top surface temperature, and thermocouple $T_{3}$ is used to measure bottom temperature of the carbon steel plate.

Figure 10: Final pressure in the FDHS samples after 30 minutes of heating and 30 minutes of cooling. Description of samples is given in Table 1. Samples 1, 8, 11, 14, and 15 generated minimal amount of hydrogen or no hydrogen (indicated with green circles).

Figure 11: A photograph of the evaporator wick for sample 8 (tested with Inorganic Aqueous Solution or IAS). Dashed circle indicates the location of the evaporator (area underneath the heater). Yellow-to-dark brown wick color could be observed within the evaporator area indicating depositions of IAS elements on the aluminum wick surface.

Figure 12: Microscopy of the wick coating. (a) Electroless Nickel plating, (b) Hard Anodized Coating. The coating was observed only on the first layer of particles indicating that the wick coating did not penetrate into the wick. This could explain why coated wicks failed to prevent hydrogen generation.

Figure 13: Thermal Resistances for $300 \mathrm{~mm} \times 150 \mathrm{~mm}$ FDHS samples tested with different working fluids at two heat loads. Description of samples is given in Table 1. During the low heat load $(240 \mathrm{~W})$, the pressure relief valve (PRV) was capped (closed) and during the high heat load test (440W), the PRV was allowed to open. Samples 8, 11, and 14 had lower thermal resistance than solid aluminum block of the same size and also produced insignificant amount of hydrogen (indicated with green circles).

Figure 14: Temperature contours for $300 \mathrm{~mm} x 150 \mathrm{~mm}$ heat spreaders, (a) aluminum alloy 6061 block, (b) material with thermal conductivity of $370 \mathrm{~W} / \mathrm{m} \cdot \mathrm{K}$. FDHS charged with water has the same temperatures than material with thermal conductivity of $370 \mathrm{~W} / \mathrm{m} \cdot \mathrm{K}$. Effective heat transfer coefficient of $490 \mathrm{~W} / \mathrm{m}^{2} \mathrm{~K}$ was achieved with a cold plate.

Figure 15: Experimentally measured steel bottom temperatures (thermocouple $T_{3}$ ) during thermal exposure test. FDHS and AA5083 were each placed over the carbon steel plate and heated six times for 7 minutes and cooled for 8 minutes between the thermal exposures. Flame ground plane impingement temperature was $1100^{\circ} \mathrm{C}$. Unprotected carbon steel temperature 
reached maximum bottom temperature of $395^{\circ} \mathrm{C}$. The bottom temperature of the carbon steel was reduced to $103^{\circ} \mathrm{C}$ when shielded with AA5083 plate and to $94^{\circ} \mathrm{C}$ when shielded with FDHS.

Figure 16: Experimentally measured temperatures after the last heating cycle for FDHS, AA5083 plate and unprotected carbon steel plate. FDHS cools eight times faster than AA5083 plate allowing aircrafts to land on a continuous basis. Note that $25 \mathrm{~mm}$ thick FDHS is lighter than 19 mm thick AA5083 plate.

Figure 17: Modeled and experimentally measured temperatures $T_{2}$ and $T_{3}$ for the first heating cycle for different heat spreaders. The results show that the lowest top surface temperature are achieved with $25 \mathrm{~mm}$ thick AA5454 plate, while the highest cooling rate and the lowest carbon steel bottom temperatures are achieved with the FDHS. Note that weights for $610 \mathrm{~mm} \times 610 \mathrm{~mm}$ heat spreaders are: $25.4 \mathrm{~kg}$ for $25 \mathrm{~mm}$ thick AA5454, $18.8 \mathrm{~kg}$ for $19 \mathrm{~mm}$ thick AA5083, and 15.7 kg for $25 \mathrm{~mm}$ thick FDHS.

\section{Table Captions}

Table 1: Combinations of samples and working fluids for working fluid compatibility tests.

Table 2: Performance comparison for solid aluminum (AA6061) and selected FDHS samples. $T_{\text {evap }}$ is evaporator wall temperature measured under the heater, $T_{\text {cond }}$ is condenser wall temperature measured under the cold plate, $T_{\text {coolant }}$ is average chilled water temperature, $Q$ is applied heat load, $q$ is applied heat flux, $R_{\text {evap-cond }}$ is the FDHS thermal resistance and $k_{\text {eff, }}$, the effective thermal conductivity of the sample. 


\section{Tables}

Table 1: Combinations of samples and working fluids for working fluid compatibility tests.

\begin{tabular}{|c|c|c|l|l|l|}
\hline Sample & $\begin{array}{c}\text { Panel thermal } \\
\text { conductivity* } \\
(\mathbf{W} / \mathbf{m} \cdot \mathbf{K})\end{array}$ & Wick & \multicolumn{1}{|c|}{$\begin{array}{c}\text { Coating / Wick } \\
\text { coating }\end{array}$} & Working Fluid & pH \\
\hline 1 & 117 & no & Hard anodization & water & 7 \\
\hline 2 & 134 & yes & n/a & water & 7 \\
\hline 3 & 117 & yes & n/a & water & 7 \\
\hline 4 & 134 & yes & n/a & water & 7 \\
\hline 5 & 117 & yes & n/a & water & 7 \\
\hline 6 & 134 & yes & Electroless Ni plating & water & 7 \\
\hline 7 & 134 & yes & Hard anodization & water & 6 \\
\hline 8 & 134 & yes & n/a & Inorganic Aqueous Solution [12] & 5 \\
\hline 9 & 134 & yes & n/a & $\begin{array}{l}150 p p m \text { chromic acid }\left(\mathrm{CrO}_{3}\right)+\text { water } \\
{[13]}\end{array}$ & 10 \\
\hline 10 & 117 & yes & n/a & 500 ppm S10+ water [14] & 7 \\
\hline 11 & 117 & yes & n/a & $1 \%$ VpCl-308+ water [14] & 5 \\
\hline 12 & 117 & yes & n/a & $50 \%$ Propylene Glycol+ water & 7 \\
\hline 13 & 117 & yes & n/a & $10 \%$ E-Passivate AL+ water [16] & 2 \\
\hline 14 & 117 & yes & n/a & Zerex automotive coolant & 7 \\
\hline 15 & 134 & yes & n/a & Iridite NCP+ water [15] & 7 \\
\hline
\end{tabular}

*Panel thermal conductivity is $134 \mathrm{~W} / \mathrm{m} \cdot \mathrm{K}$ for AA5454 and $117 \mathrm{~W} / \mathrm{m} \cdot \mathrm{K}$ for AA5083 from reference [18]

Table 2: Performance comparison for solid aluminum (AA6061) and selected FDHS samples.

$T_{\text {evap }}$ is evaporator wall temperature measured under the heater, $T_{\text {cond }}$ is condenser wall temperature measured under the cold plate, $T_{\text {coolant }}$ is average chilled water temperature, $Q$ is applied heat load, $q$ is applied heat flux, $R_{\text {evap-cond }}$ is the FDHS thermal resistance and $k_{\text {eff, }}$ the effective thermal conductivity of the sample.

\begin{tabular}{|c|c|c|c|c|c|c|c|c|c|}
\hline Sample & $\begin{array}{c}\mathbf{k}_{\text {panel }}{ }^{*} \\
(\mathbf{W} / \mathbf{m} \cdot \mathbf{K})\end{array}$ & Working Fluid & $\begin{array}{l}\mathbf{T}_{\text {evap }} \\
\left({ }^{\circ} \mathrm{C}\right)\end{array}$ & $\begin{array}{l}\mathbf{T}_{\text {cond }} \\
\left({ }^{\circ} \mathrm{C}\right)\end{array}$ & $\begin{array}{l}\mathbf{T}_{\text {coolant }} \\
\left({ }^{\circ} \mathbf{C}\right)\end{array}$ & $\begin{array}{c}\mathbf{Q} \\
(\mathbf{W})\end{array}$ & $\underset{\left(W / \mathbf{c m}^{2}\right)}{\mathbf{q}}$ & $\begin{array}{c}\mathbf{R}_{\text {evap-cond }} \\
\text { (K/W) }\end{array}$ & $\begin{array}{c}\mathbf{k}_{\text {eff }} \\
(\mathbf{W} / \mathbf{m} \cdot \mathbf{K})\end{array}$ \\
\hline AA6061 & 167 & $\mathrm{n} / \mathrm{a}$ & 210 & 71 & 21 & 435 & 28 & 0.32 & 167 \\
\hline 4 & 134 & DI water & 157 & 91 & 22 & 461 & 30 & 0.14 & 370 \\
\hline 8 & 134 & $\begin{array}{l}\text { Inorganic } \\
\text { Aqueous Solution }\end{array}$ & 166 & 92 & 21 & 459 & 30 & 0.16 & 310 \\
\hline 11 & 117 & $\begin{array}{l}1 \% \mathrm{VpCl}-308+ \\
\text { DI water }\end{array}$ & 179 & 90 & 21 & 438 & 28 & 0.20 & 240 \\
\hline 14 & 117 & $\begin{array}{l}10 \% \text { E-Passivate } \\
\text { AL+ DI water }\end{array}$ & 182 & 93 & 21 & 448 & 29 & 0.20 & 240 \\
\hline 15 & 134 & $\begin{array}{l}\text { Zerex automotive } \\
\text { coolant }\end{array}$ & 221 & 76 & 20 & 411 & 26 & 0.35 & 135 \\
\hline
\end{tabular}

$* \mathrm{k}_{\text {panel }}$ (panel thermal conductivity) is $167 \mathrm{~W} / \mathrm{mK}$ for AA6061, 134W/mK for AA5454, and $117 \mathrm{~W} / \mathrm{mK}$ for AA5083 from reference [18]. 


\section{Figures and Figure Captions}

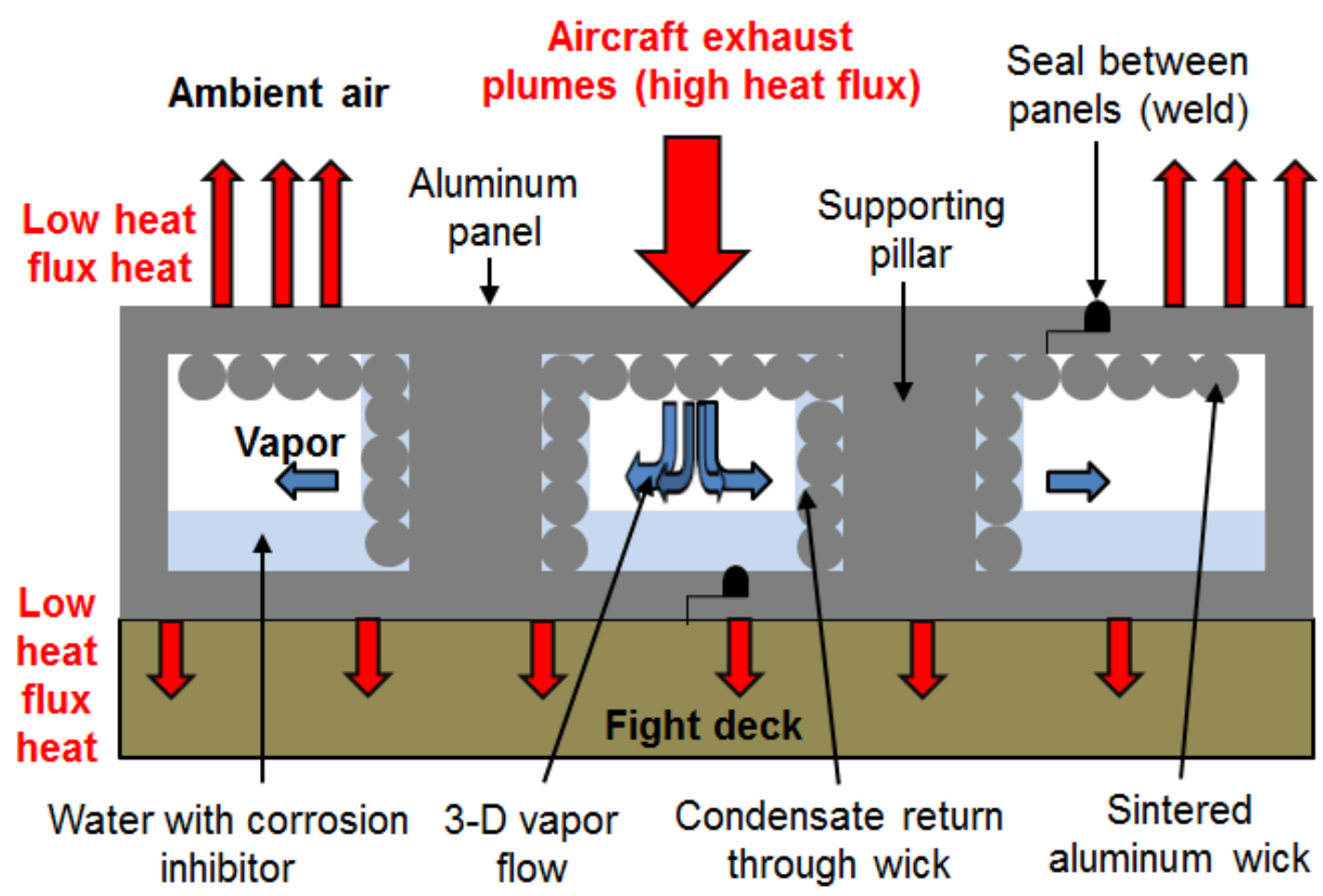

Figure 1: Flight Deck Heat Spreader (FDHS). Aircraft exhaust plumes impinge on top panel and vaporize working fluid absorbed in sintered aluminum wick; vapor spreads the heat to panels away from the heat source, and rejects the heat to ambient and flight deck at low heat flux over a large area. Working fluid condenses and drips into a liquid pool formed on the bottom of the FDHS and the condensate is wicked back to the evaporator wick located underneath the heat source. 


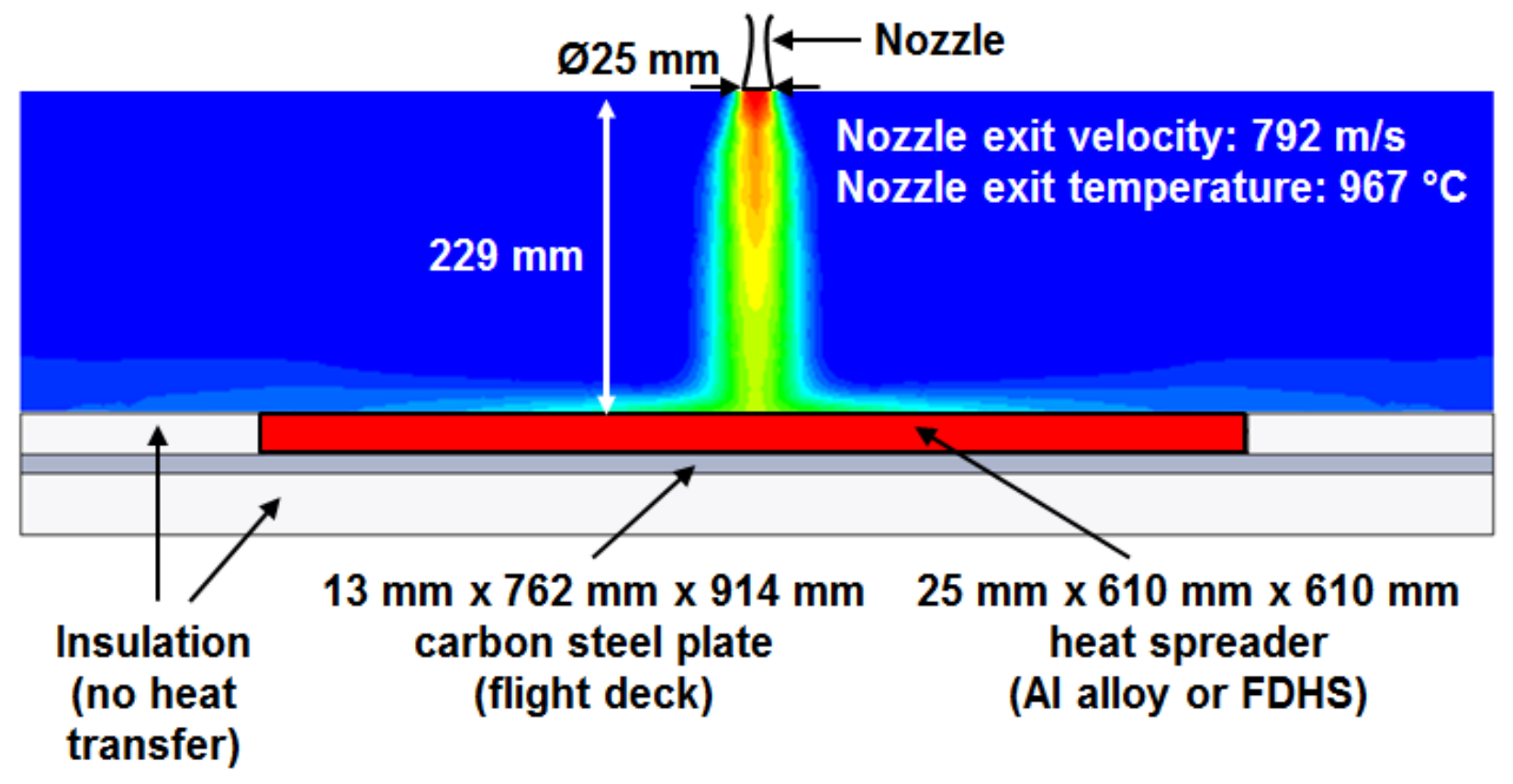

Figure 2: Geometry and boundary conditions of subscale flight deck thermal model. Nozzle exit velocity is $792 \mathrm{~m} / \mathrm{s}$ and nozzle exit temperature is $977^{\circ} \mathrm{C}$. Nozzle diameter is $25 \mathrm{~mm}$ and nozzle height is $229 \mathrm{~mm}$. Carbon steel plate size is $13 \mathrm{~mm} \times 762 \mathrm{~mm} \times 914 \mathrm{~mm}$ and heat spreader size is $25 \mathrm{~mm} \times 610 \mathrm{~mm} \times 610 \mathrm{~mm}$. 


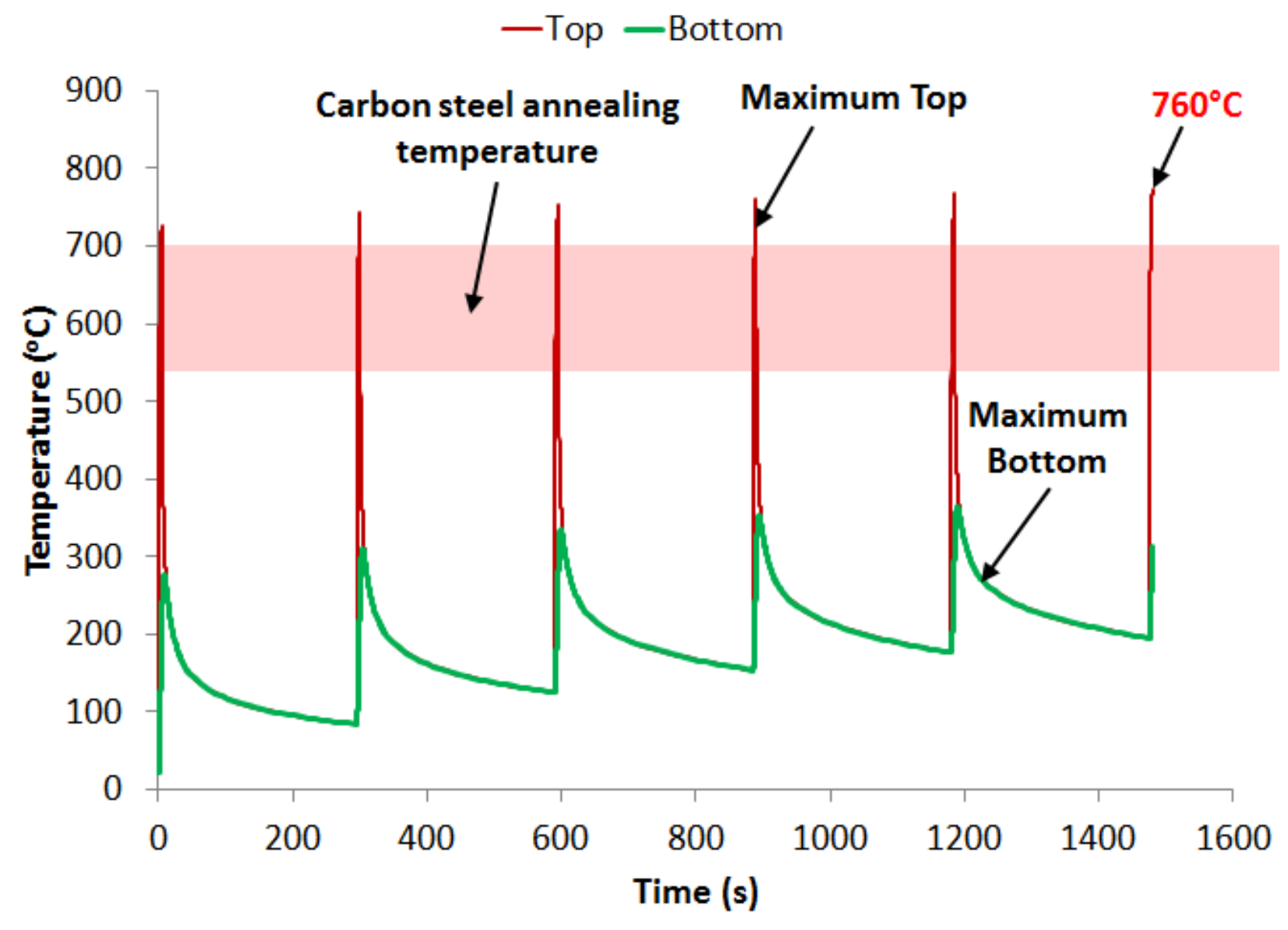

Figure 3: Temperature history of maximum top and bottom temperatures of carbon steel flight deck. Carbon steel flight deck was subjected to 5 seconds long thermal exposures with hot air at $967^{\circ} \mathrm{C}$ and air velocity $792 \mathrm{~m} / \mathrm{s}$. Maximum top plate temperature reached $760^{\circ} \mathrm{C}$ and maximum bottom plate temperature $360^{\circ} \mathrm{C}$. 


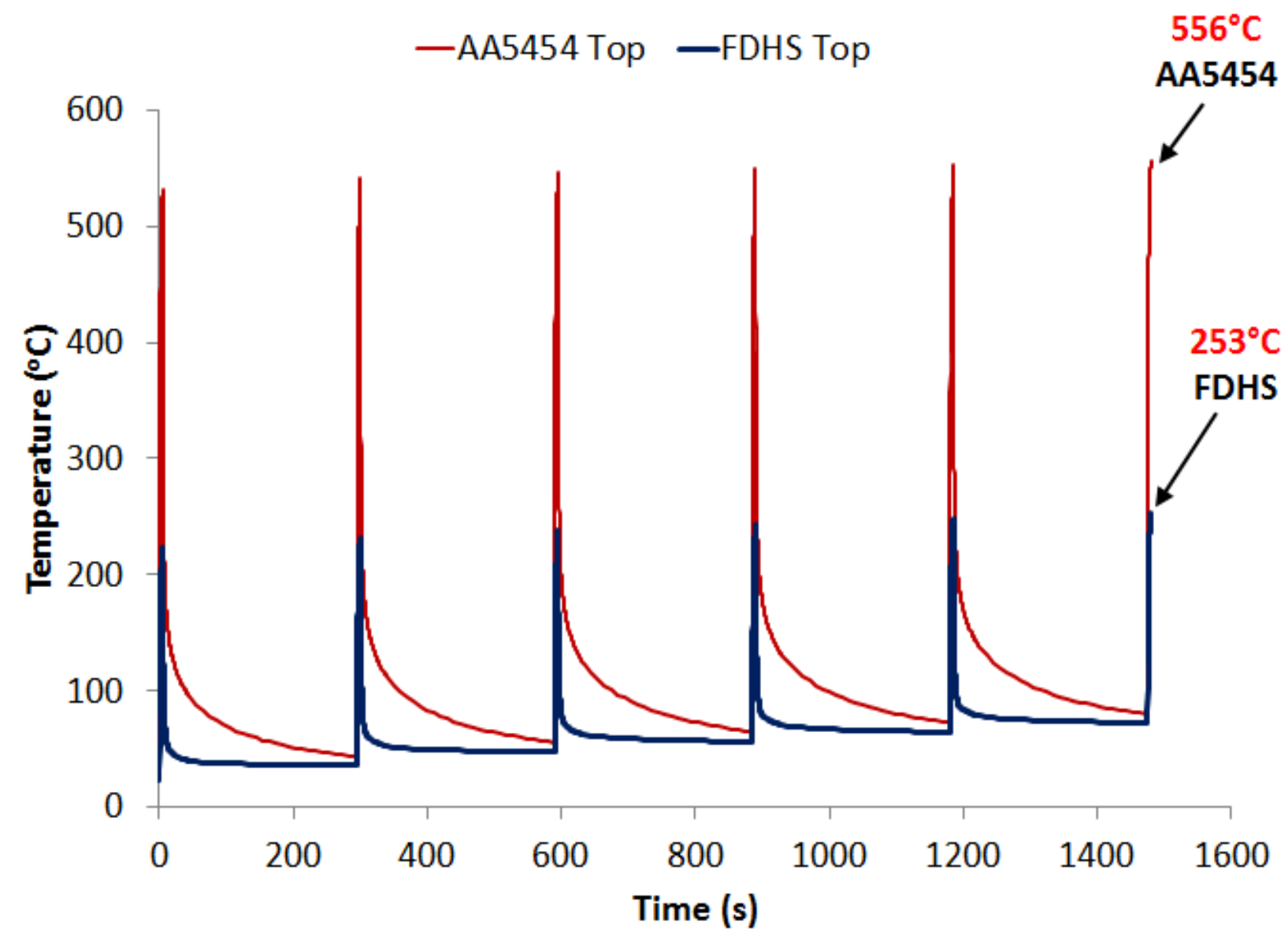

Figure 4: Temperature history of maximum AA5454 and FDHS top temperatures. FDHS and AA5454 were both subjected to 5 seconds long thermal exposures with hot air at $967^{\circ} \mathrm{C}$ and air velocity $792 \mathrm{~m} / \mathrm{s}$. Maximum top plate temperature reached $556{ }^{\circ} \mathrm{C}$ for AA5454 plate and $253{ }^{\circ} \mathrm{C}$ for FDHS. 

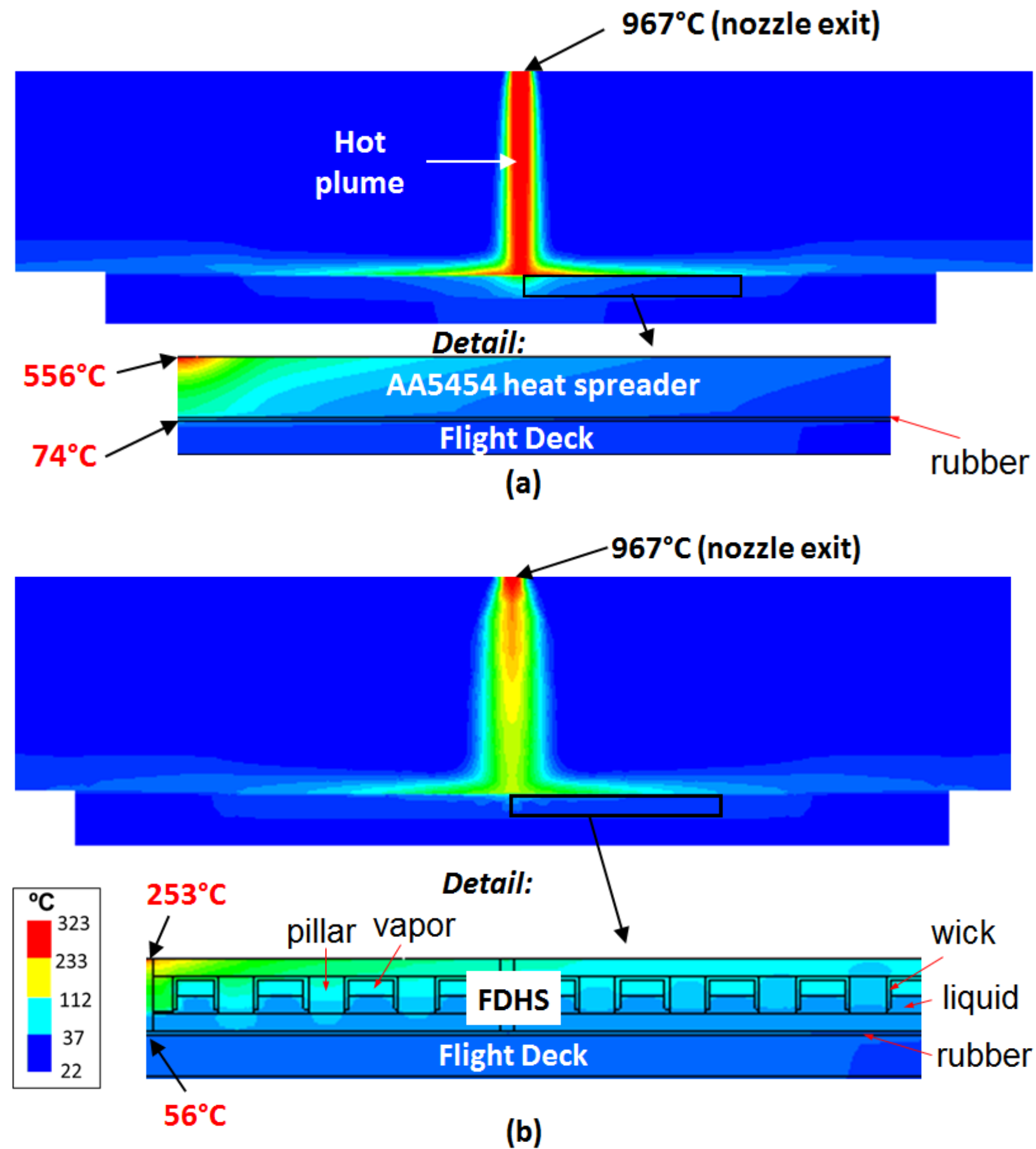

Figure 5: Temperature contours at the end of the last sixth heating cycle; (a) AA5454 plate, (b) FDHS heat spreader. Maximum top surface temperature reached $556^{\circ} \mathrm{C}$ for the AA5454 plate and $253{ }^{\circ} \mathrm{C}$ for the FDHS. Maximum bottom surface temperature reached $74{ }^{\circ} \mathrm{C}$ for the AA5454 plate and $56^{\circ} \mathrm{C}$ for the FDHS. 


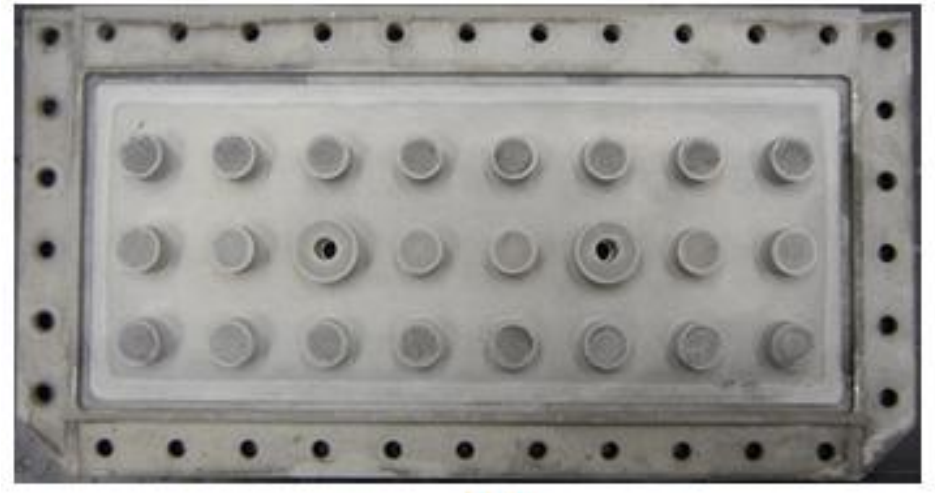

(a)

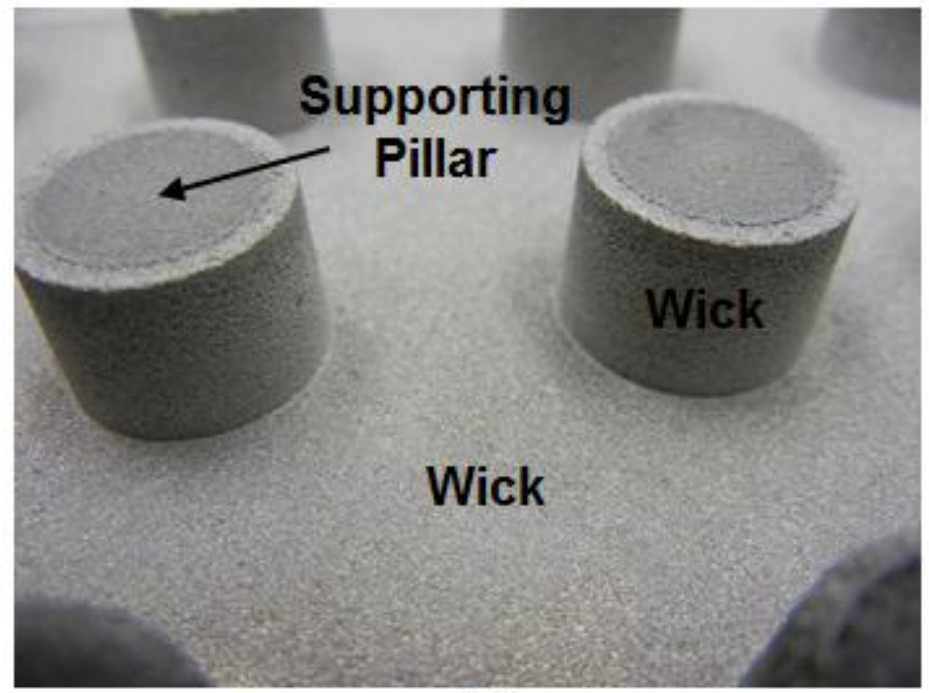

(b)

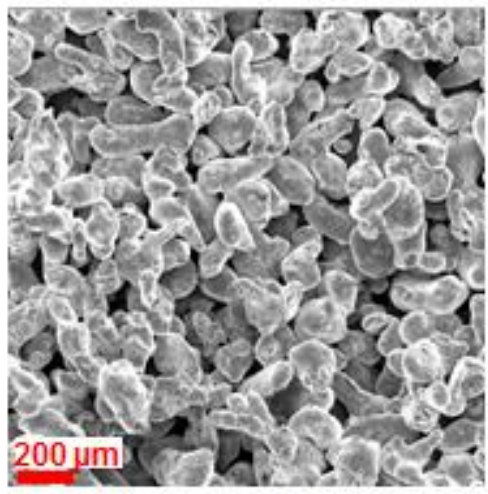

(c)

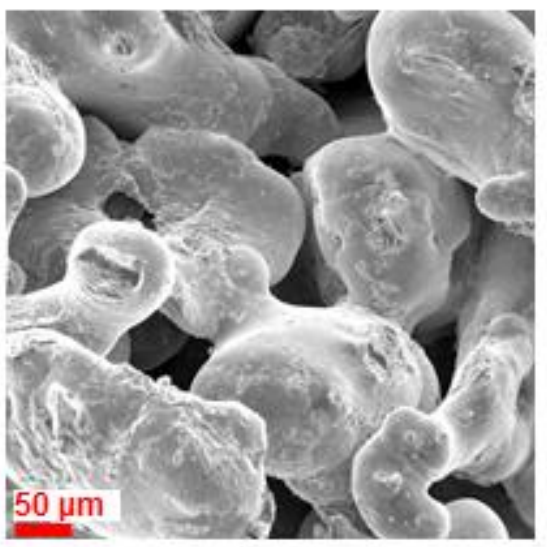

(d)

Figure 6: Aluminum powder wick sintered to one of the FDHS top panels. (a) Photograph of a $300 \mathrm{~mm} \times 150 \mathrm{~mm}$ FDHS panel with wick, (b) a close-up photograph of supporting pillars with wick, $(c)$ and $(d)$ are scanning electron microscope photographs of the wick fracture showing individual particle-to-particle contacts. 


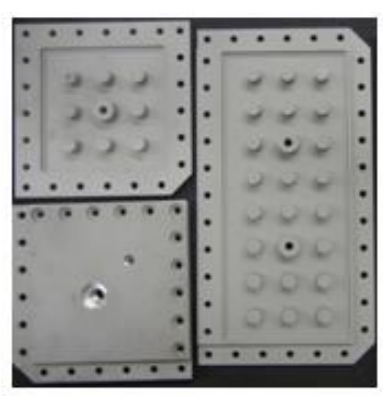

(a)

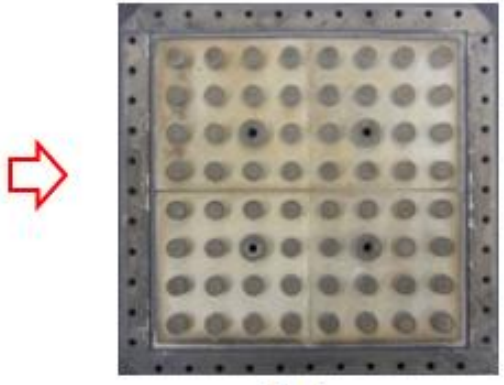

(b)

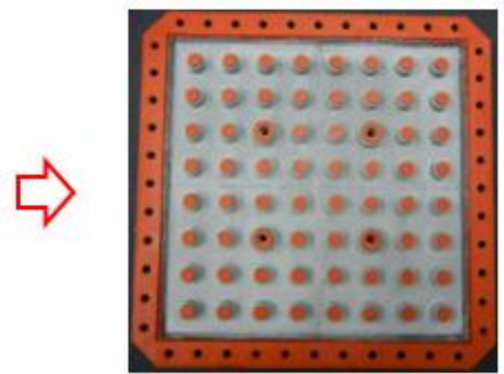

(c)

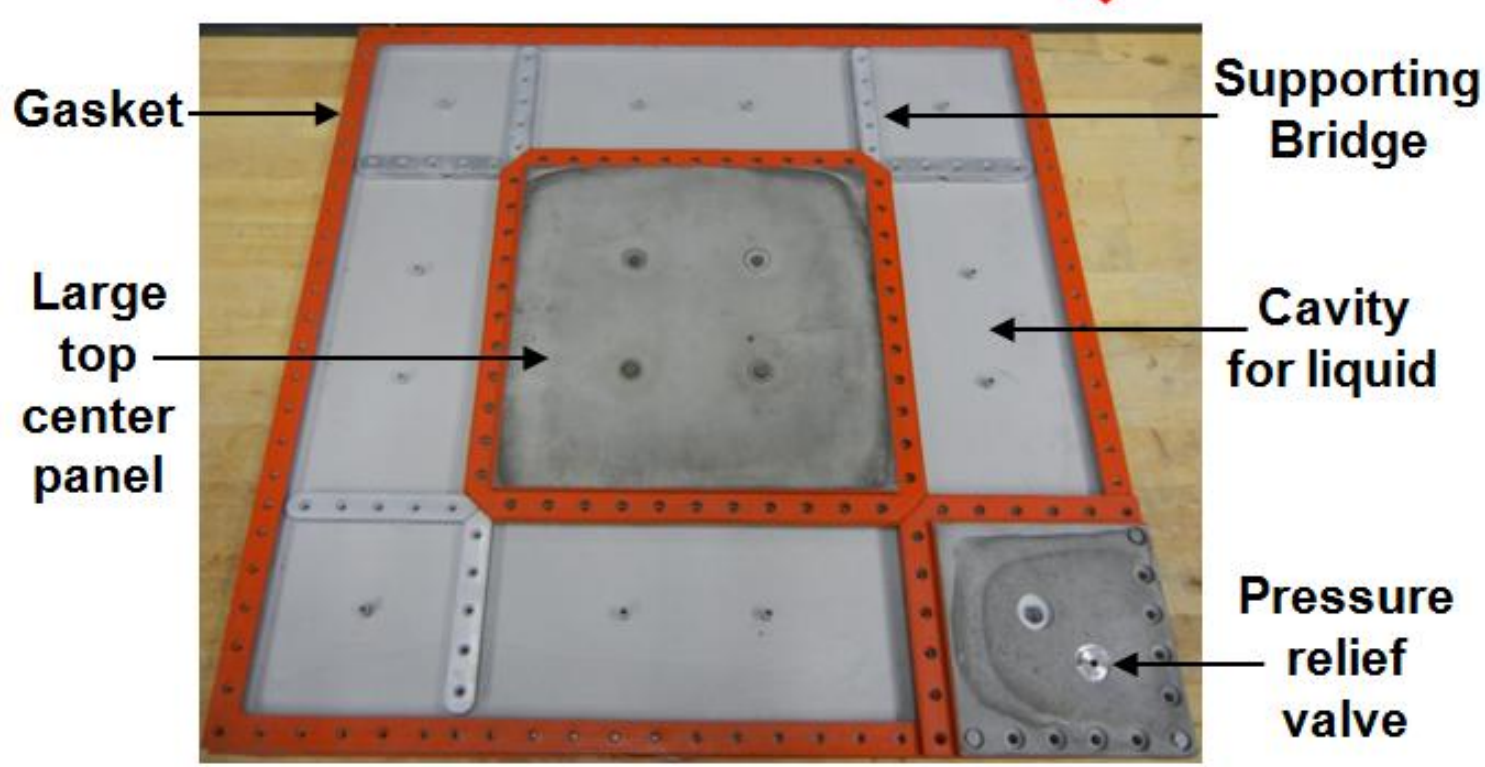

(d)

Figure 7: FDHS fabrication and assembly steps. (a) Panel machining, (b) wick fabrication, (c) gasket adhesion to a panel, (d) FDHS liquid charging and panel assembly (for clarity only two of the nine top panels are shown). 


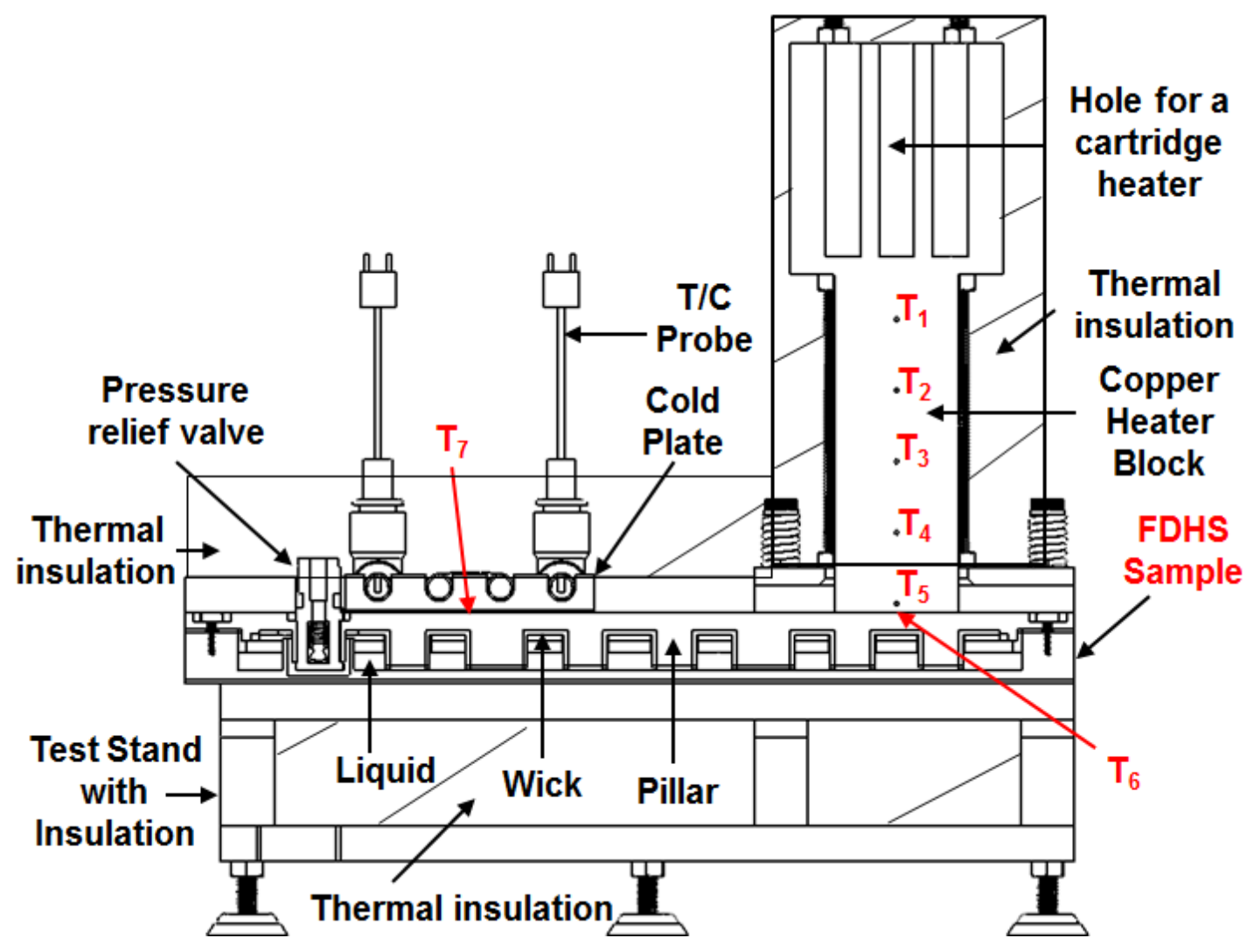

Figure 8: Test setup for working fluid compatibility tests. Heater block with an array of equally spaced thermocouples $T_{1}$ to $T_{5}$ is used to measure the heat flux into the FDHS sample.

Evaporator surface temperature is measured with thermocouple $T_{6}$. A cold plate is used to remove the heat from the FDHS sample. Condenser temperature is measured with thermocouple $T_{7}$. Internal pressure of the sample is monitored with a pressure transducer (not shown for clarity). 


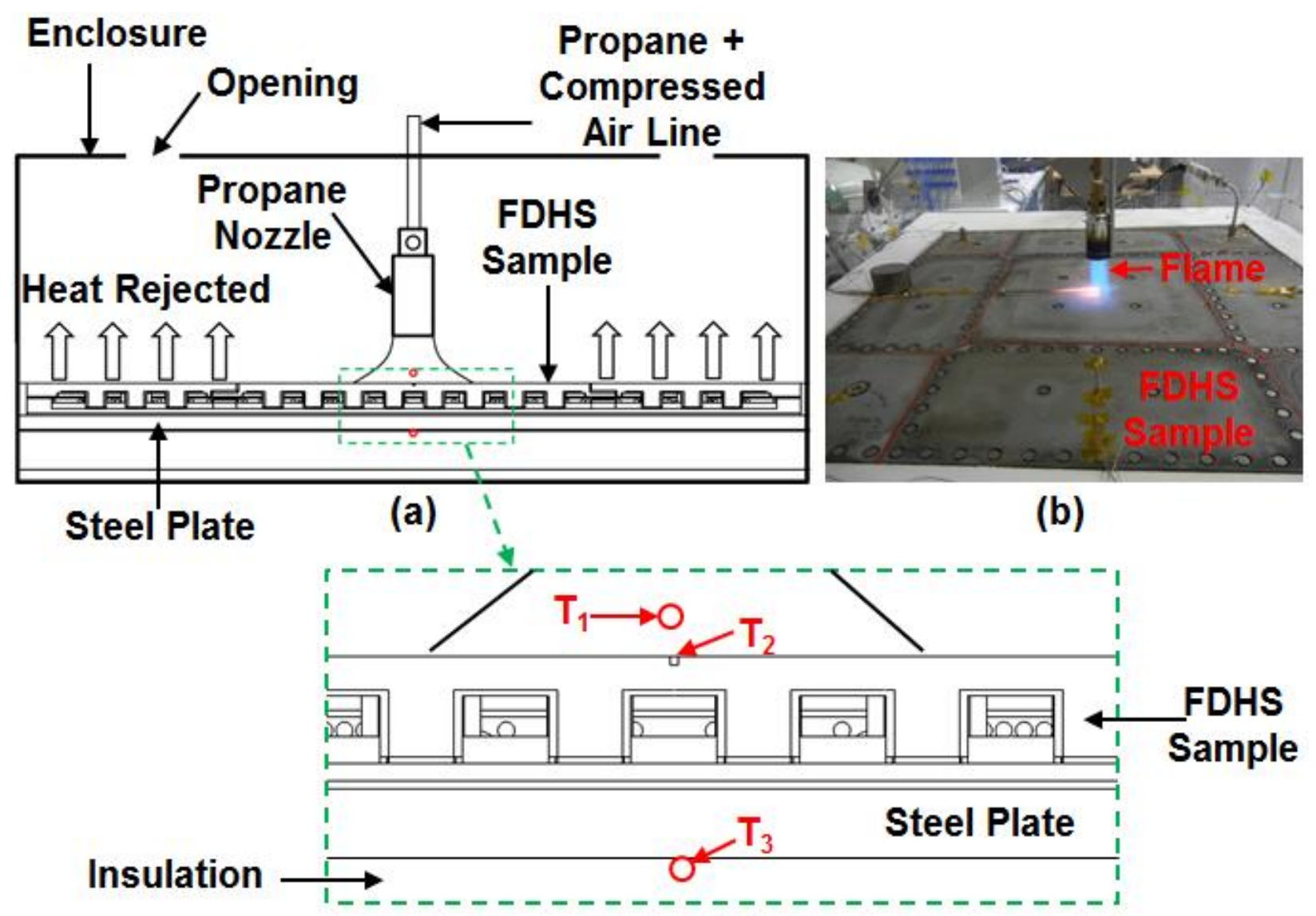

(c)

Figure 9: Thermal exposure test bed. (a) Schematic of the thermal exposure test setup. FDHS sample is placed on a carbon steel plate that simulates a flight deck. Propane torch is used to heat the sample. Flame impinges on the FDHS and the FDHS spreads the heat and shields the carbon steel plate. (b) Photograph of the test bed. (c) Detail of the heat impingement zone showing the locations of the thermocouples. Thermocouple $T_{1}$ is used to measure ground plane impingement temperature, thermocouple $T_{2}$ is used to measure sample top surface temperature, and thermocouple $T_{3}$ is used to measure bottom temperature of the carbon steel plate. 


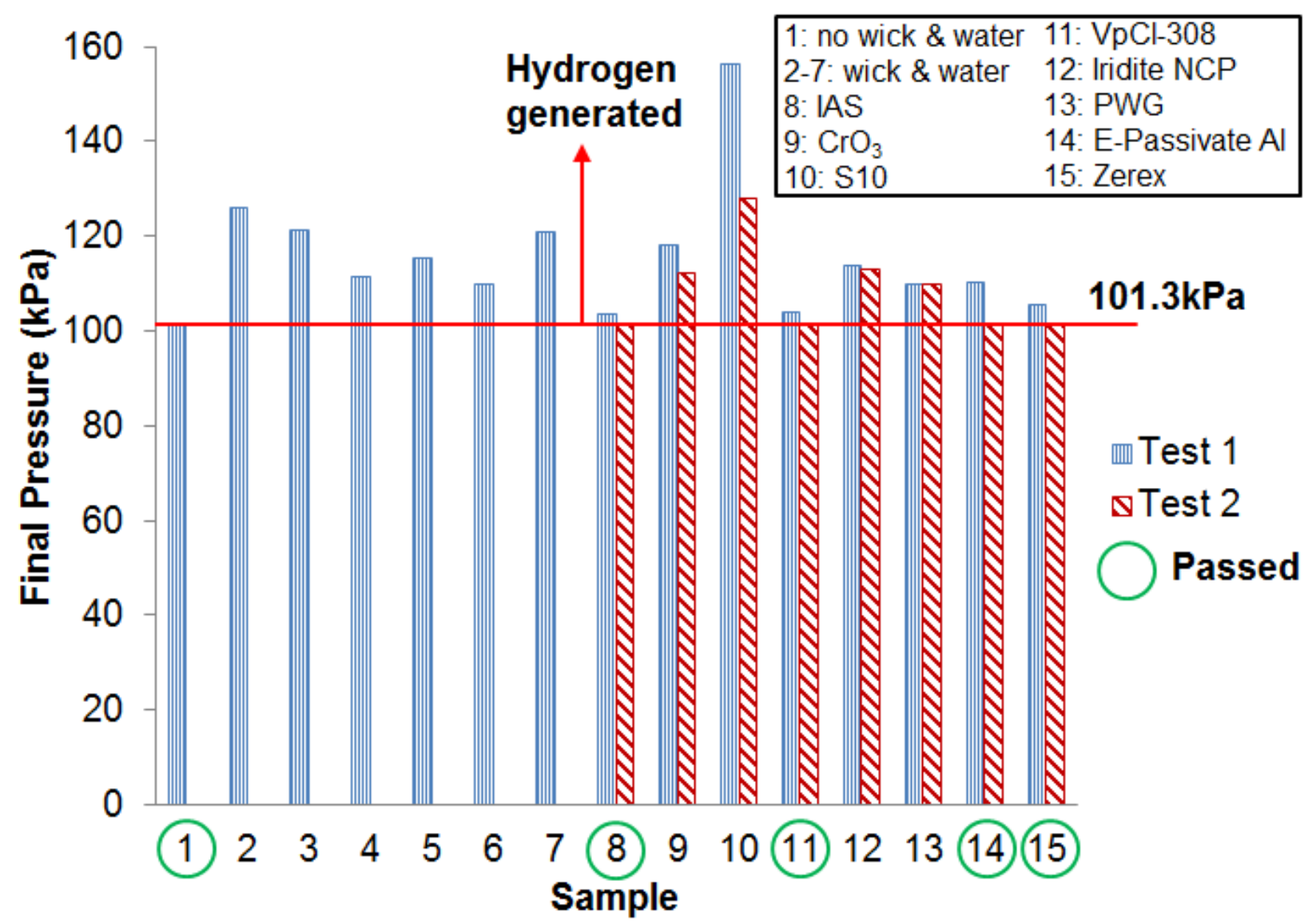

Figure 10: Final pressure in the FDHS samples after 30 minutes of heating and 30 minutes of cooling. Description of samples is given in Table 1. Samples 1, 8, 11, 14, and 15 generated minimal amount of hydrogen or no hydrogen (indicated with green circles). 


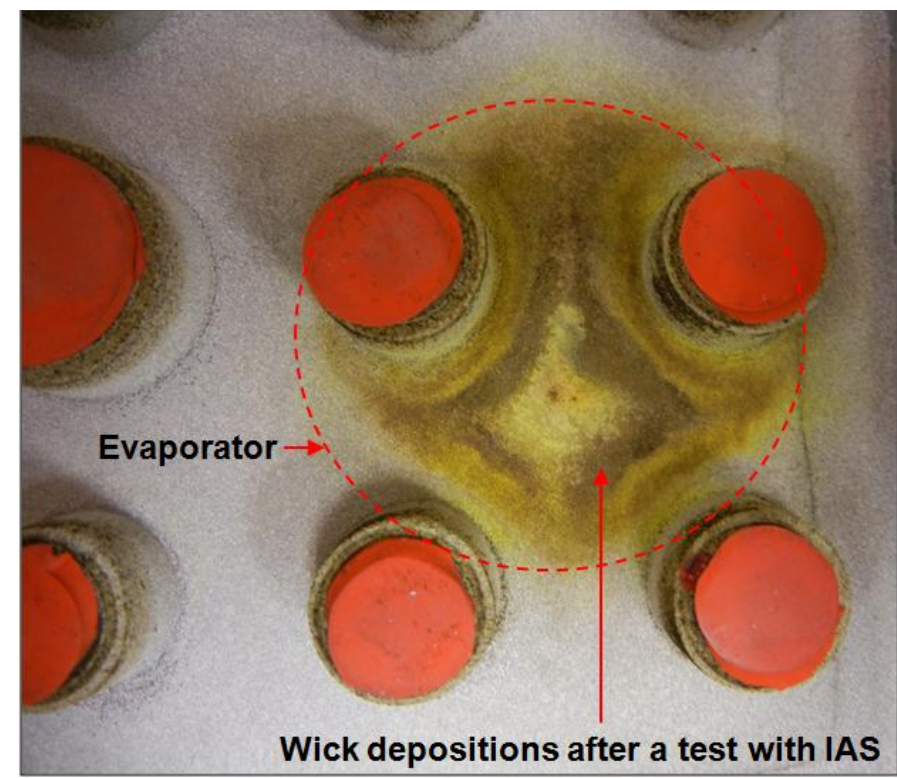

Figure 11: A photograph of the evaporator wick for sample 8 (tested with Inorganic Aqueous Solution or IAS). Dashed circle indicates the location of the evaporator (area underneath the heater). Yellow-to-dark brown wick color could be observed within the evaporator area indicating depositions of IAS elements on the aluminum wick surface. 


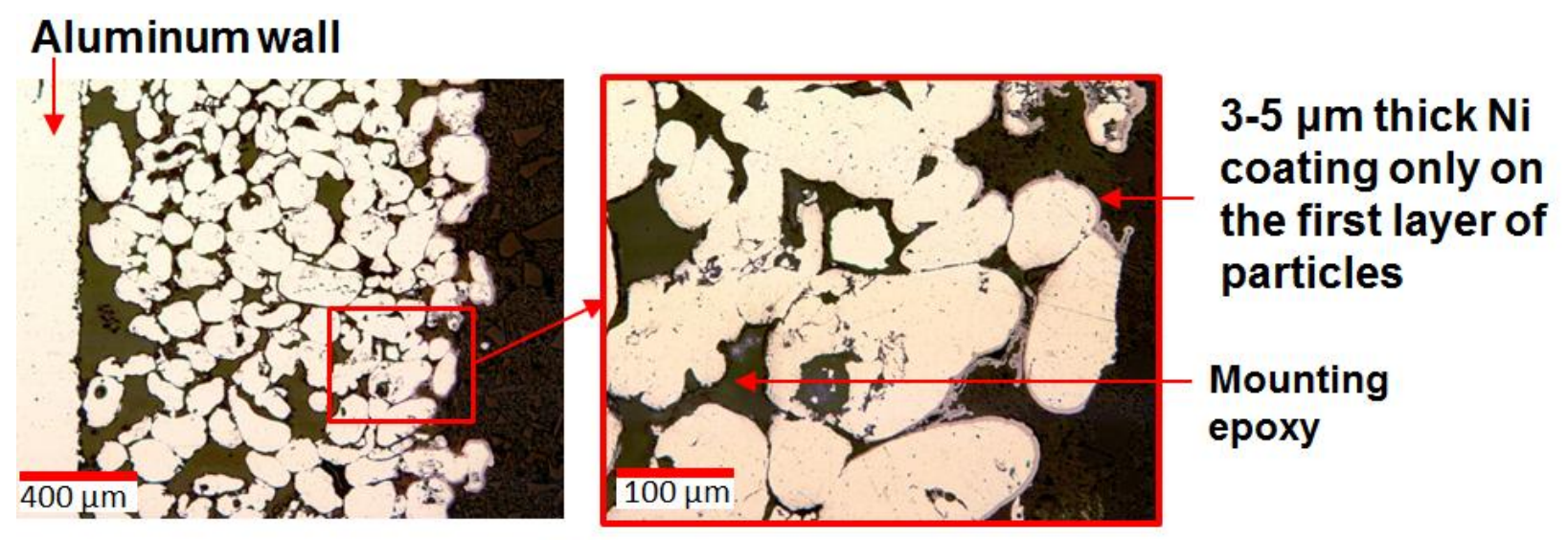

Aluminum wall

(a)
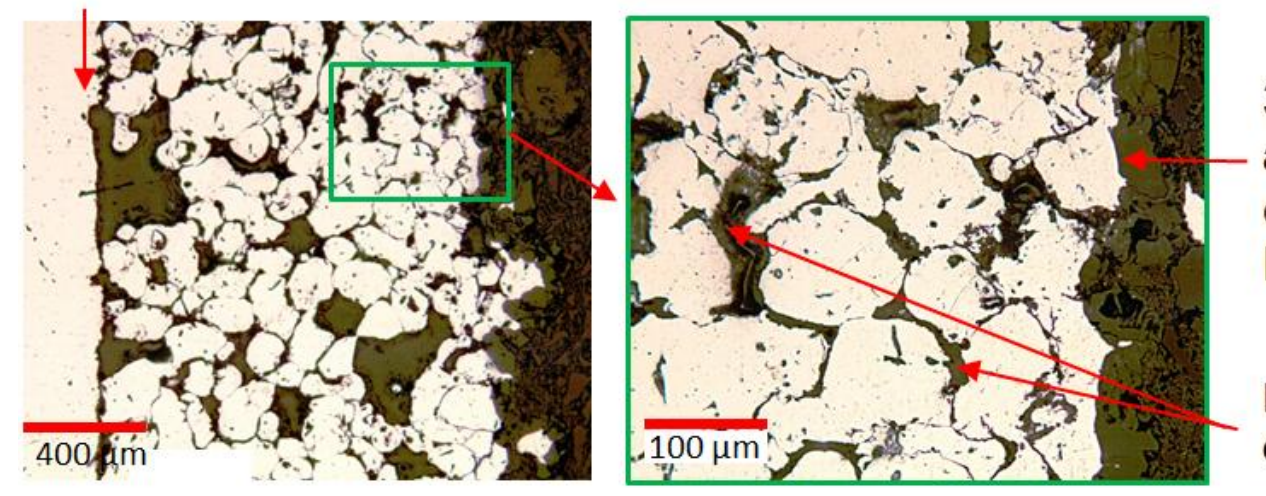

30-40 $\mu \mathrm{m}$ thick anodized coating only on the first layer of particles

(b)

Figure 12: Microscopy of the wick coating. (a) Electroless Nickel plating, (b) Hard Anodized Coating. The coating was observed only on the first layer of particles indicating that the wick coating did not penetrate into the wick. This could explain why coated wicks failed to prevent hydrogen generation. 


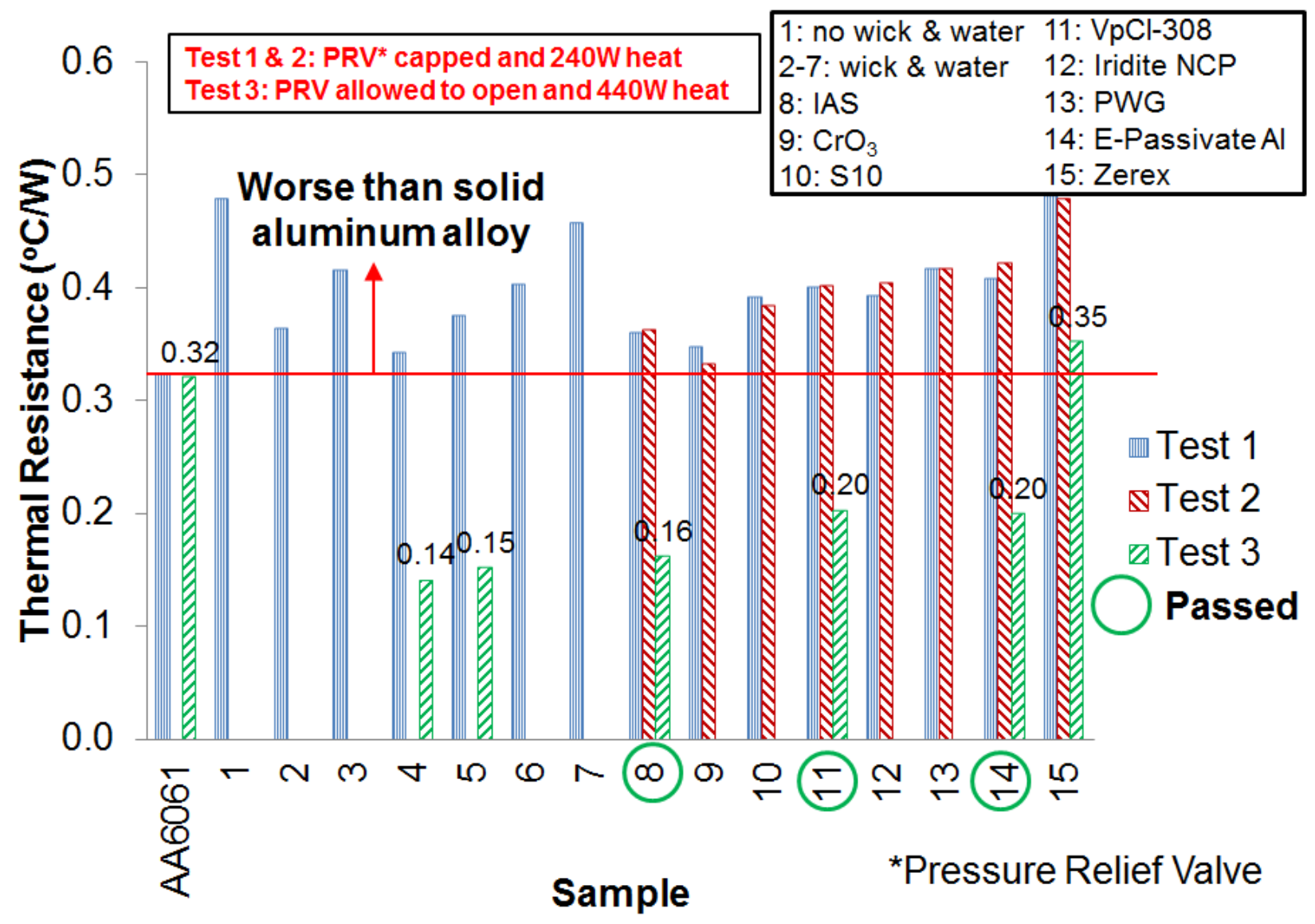

Figure 13: Thermal Resistances for $300 \mathrm{~mm} \times 150 \mathrm{~mm}$ FDHS samples tested with different working fluids at two heat loads. Description of samples is given in Table 1. During the low heat load (240W), the pressure relief valve (PRV) was capped (closed) and during the high heat load test (440W), the PRV was allowed to open. Samples 8, 11, and 14 had lower thermal resistance than solid aluminum block of the same size and also produced insignificant amount of hydrogen (indicated with green circles). 


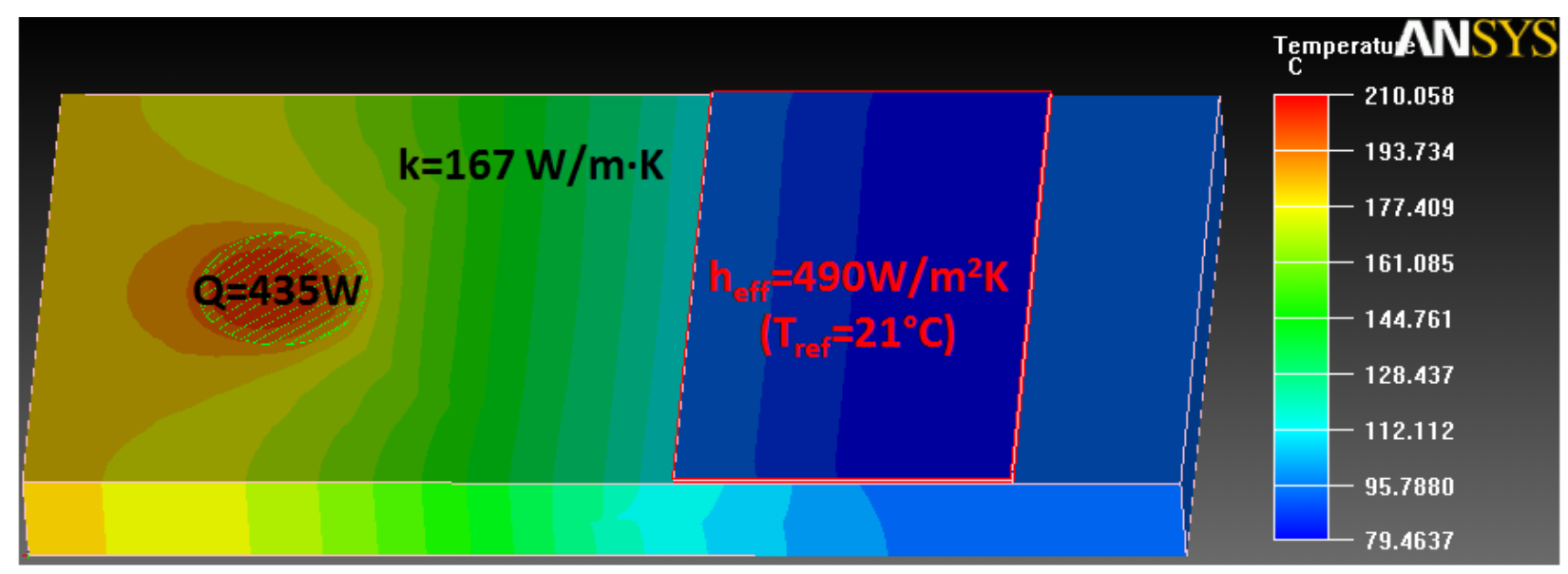

(a)

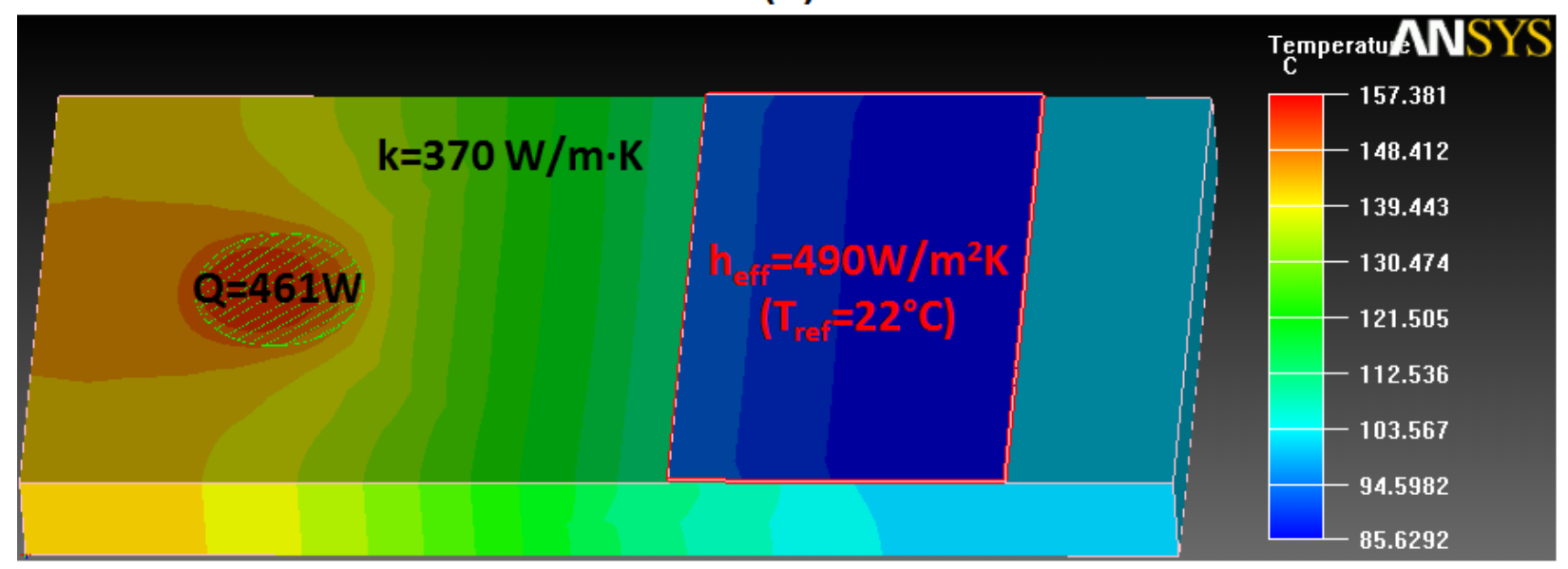

(b)

Figure 14: Temperature contours for $300 \mathrm{~mm} x 150 \mathrm{~mm}$ heat spreaders, (a) aluminum alloy 6061 block, (b) material with thermal conductivity of $370 \mathrm{~W} / \mathrm{m} \cdot \mathrm{K}$. FDHS charged with water has the same temperatures than material with thermal conductivity of $370 \mathrm{~W} / \mathrm{m} \cdot \mathrm{K}$. Effective heat transfer coefficient of $490 \mathrm{~W} / \mathrm{m}^{2} \mathrm{~K}$ was achieved with a cold plate. 


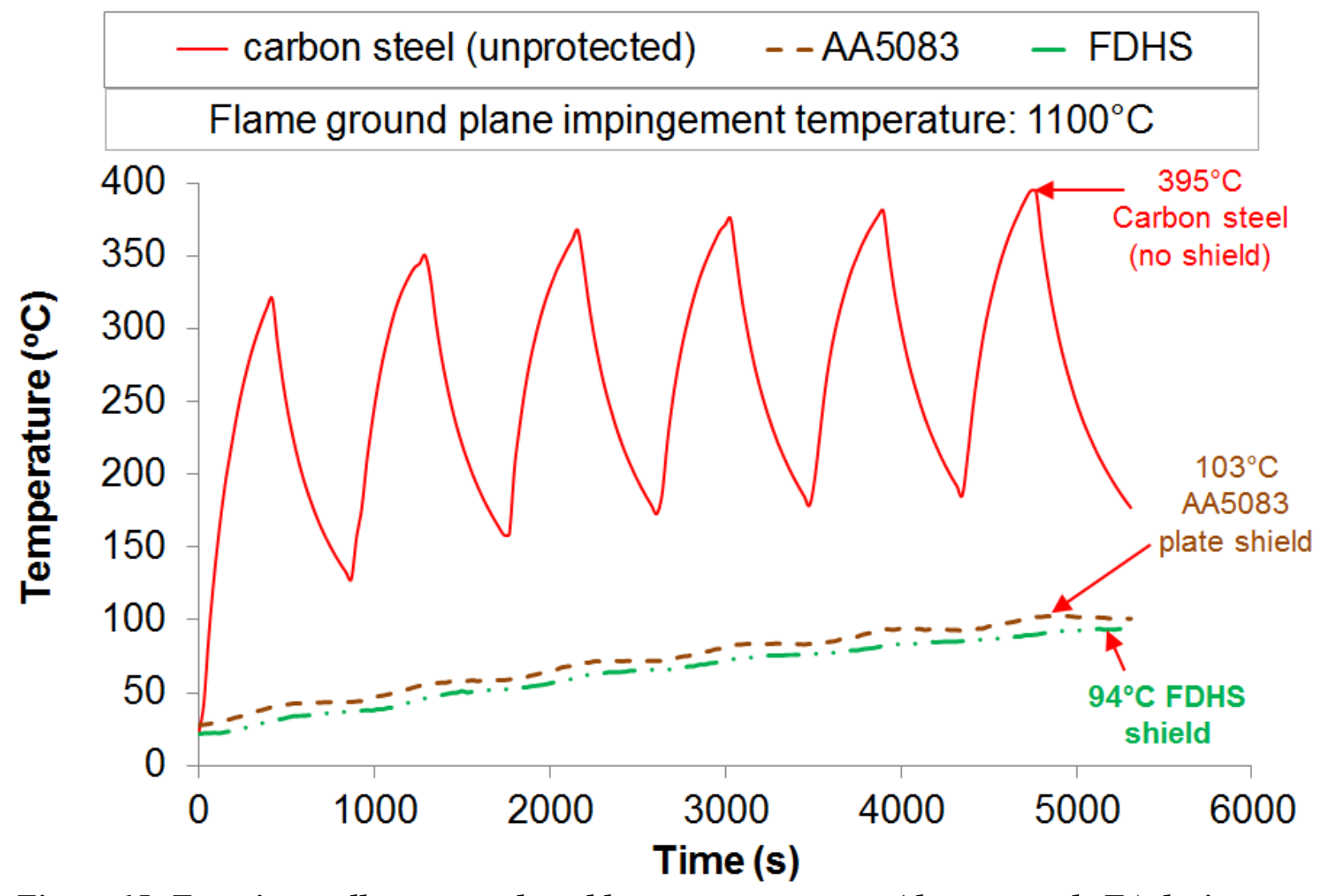

Figure 15: Experimentally measured steel bottom temperatures (thermocouple $T_{3}$ ) during thermal exposure test. FDHS and AA5083 were each placed over the carbon steel plate and heated six times for 7 minutes and cooled for 8 minutes between the thermal exposures. Flame ground plane impingement temperature was $1100^{\circ} \mathrm{C}$. Unprotected carbon steel temperature reached maximum bottom temperature of $395^{\circ} \mathrm{C}$. The bottom temperature of the carbon steel was reduced to $103^{\circ} \mathrm{C}$ when shielded with AA5083 plate and to $94^{\circ} \mathrm{C}$ when shielded with FDHS. 


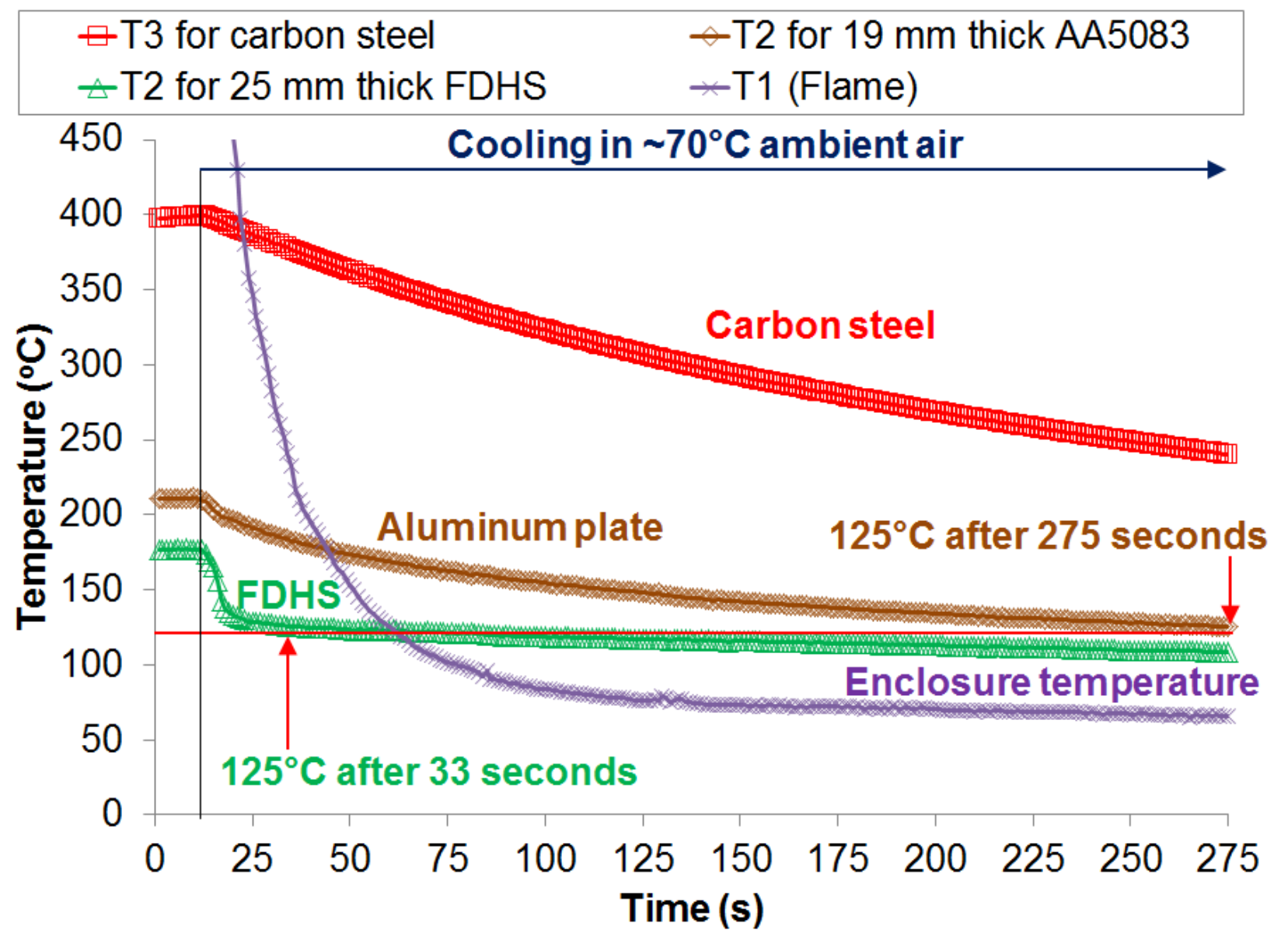

Figure 16: Experimentally measured temperatures after the last heating cycle for FDHS, AA5083 plate and unprotected carbon steel plate. FDHS cools eight times faster than AA5083 plate allowing aircrafts to land on a continuous basis. Note that $25 \mathrm{~mm}$ thick FDHS is lighter than $19 \mathrm{~mm}$ thick AA5083 plate. 


\begin{tabular}{|cc|}
\hline $\begin{array}{c}- \text { T2 for } 1.9 \mathrm{~cm} \text { AA5083 Experiment } \\
\text { - T2 for } 2.5 \mathrm{~cm} \text { MHS Experiment }\end{array}$ & $\diamond$ T3 for $1.9 \mathrm{~cm}$ AA5083 Experiment \\
\hline--- T2 for $1.9 \mathrm{~cm}$ AA5083 Simulation & - T3 for $2.5 \mathrm{~cm}$ MHS Experiment \\
\hline T2 for $2.5 \mathrm{~cm}$ AA5454 Simulation & $-\cdot$ T3 for $2.5 \mathrm{~cm}$ AA5454 Simulation \\
\hline
\end{tabular}

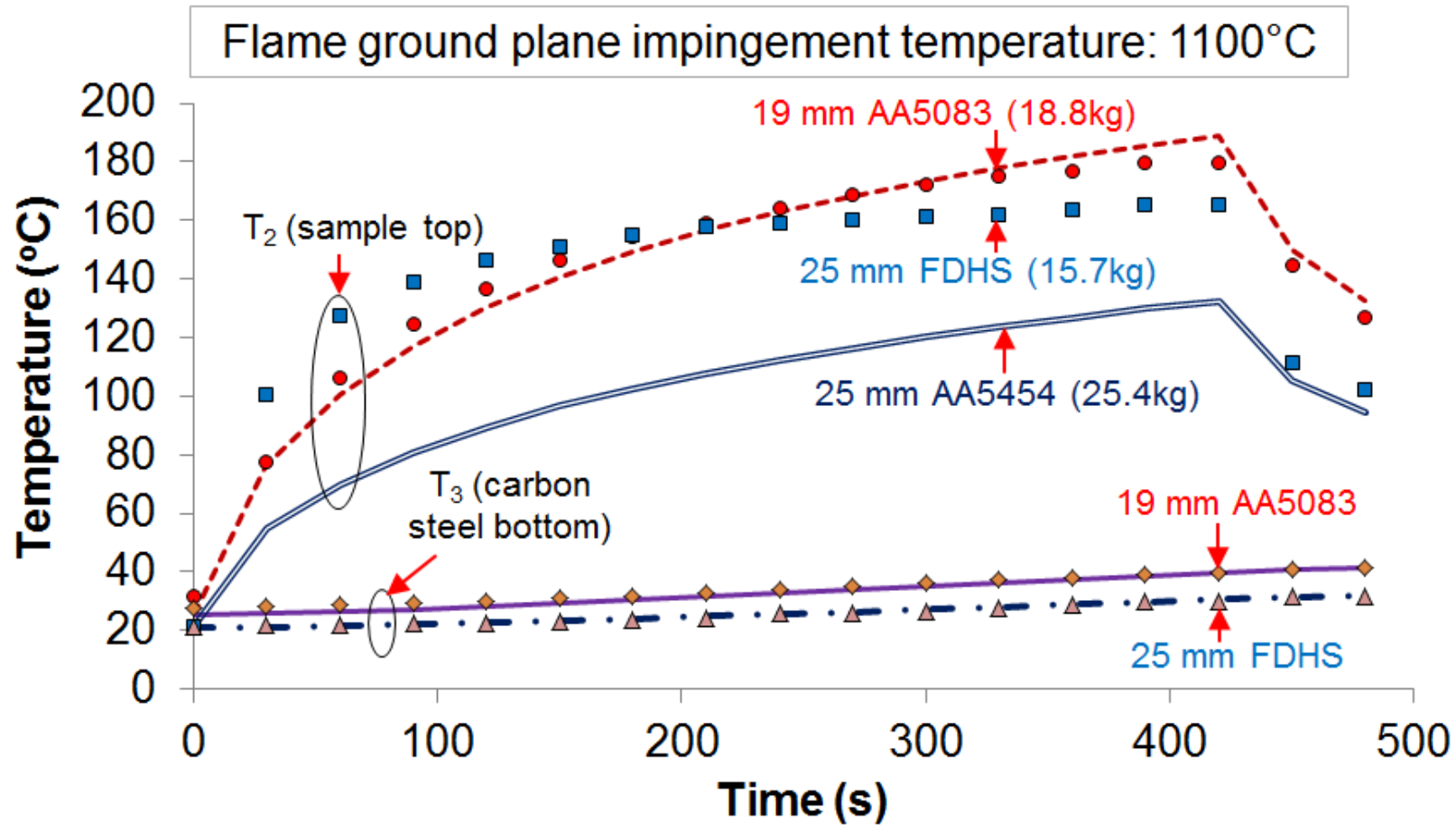

Figure 17: Modeled and experimentally measured temperatures $T_{2}$ and $T_{3}$ for the first heating cycle for different heat spreaders. The results show that the lowest top surface temperature are achieved with 25 mm thick AA5454 plate, while the highest cooling rate and the lowest carbon steel bottom temperatures are achieved with the FDHS. Note that weights for $610 \mathrm{~mm} \times 610 \mathrm{~mm}$ heat spreaders are: $25.4 \mathrm{~kg}$ for $25 \mathrm{~mm}$ thick AA5454, $18.8 \mathrm{~kg}$ for $19 \mathrm{~mm}$ thick AA5083, and 15.7 $\mathrm{kg}$ for $25 \mathrm{~mm}$ thick FDHS. 